\title{
Effects of High-Pretension Support System on Soft Rock Large Deformation of Perpendicularly Crossing Tunnels
}

\author{
Li Gan $\left(\mathbb{D},{ }^{1} \text { Ma Weibin }(\mathbb{D})^{2} \text { Tian Siming }(\mathbb{D})^{3} \text { and Zhou Wenhao }{ }^{2}\right)^{2}$ \\ ${ }^{1}$ State Key Laboratory of Hydroscience and Engineering, Tsinghua University, Beijing 100084, China \\ ${ }^{2}$ China Academy of Railway Sciences, \\ Railway Construction Research Institute of China Academy of Railway Sciences Group Co., Ltd., Beijing 100084, China \\ ${ }^{3}$ China Railway Economic and Planning Research Institute, Beijing 100084, China \\ Correspondence should be addressed to Ma Weibin; maweibin_tiekeyuan@163.com
}

Received 22 November 2020; Revised 29 November 2020; Accepted 9 December 2020; Published 21 December 2020

Academic Editor: Hualei Zhang

Copyright (c) $2020 \mathrm{Li}$ Gan et al. This is an open access article distributed under the Creative Commons Attribution License, which permits unrestricted use, distribution, and reproduction in any medium, provided the original work is properly cited.

\begin{abstract}
The control mechanism of prestressed support system is studied by means of three-dimensional discrete element numerical simulation, theoretical analysis, and field measurement. The actual project is selected to analyze, and the control effect is demonstrated. The theoretical analysis results show that the prestressed support can improve the self-bearing capacity of surrounding rock, which is conducive to the stability of the surrounding rock. The numerical calculation shows that, under the control of the long and short cables, the prestress can spread effectively and form two bearing arches. The deformation is difficult to control, which is in the arch crown and the arch shoulder of the tunnel intersection. However, the deformation of the surrounding rock decreases with the increase of prestress. Through the analysis of the measured results, it shows that the pretension support design scheme can effectively control the large deformation of the surrounding rock.
\end{abstract}

\section{Introduction}

With the implementation of the western development strategy in China and the rapid development of tunnel engineering, the proportion of long and deep tunnels is increasing. The increase of tunnel construction depth and length will inevitably face more complex geological environment. Especially, under the action of high ground stress, high seepage pressure, and excavation disturbance, the plastic deformation characteristics of soft rock are obvious. It will lead to a series of problems, such as sudden and serious malignant accidents and increased construction cost.

In the 1950s, Austrian scholars proposed a new Austrian method for underground engineering support, whose core is to maintain and utilize the self-bearing capacity of the surrounding rock $[1,2]$. Considering the complex geological conditions and construction environment of the soft rock tunnel, scholars have carried out much work on the stability of bearing body under the joint action of support and surrounding rocks. The research focuses on the support strategies of high-strength initial support system, multilevel layered support, yieldable support technology, and active support system. At present, the main methods to increase initial support system are as follows: improved concrete strength [3-6]; encrypted steel arch [7, 8]; and new arch structures $[9,10]$. Multistage layered support mainly includes advance pipe shed support $[11,12]$ and double-layer initial support [13]. The above method improves the bearing capacity of the supporting structure, effectively controls the development of the plastic area, and alleviates the large deformation of the soft rock tunnel. The above strategy does not enhance the strength of the surrounding rock. Under the action of high ground stress, the surrounding rock is prone to continuous and slow deformation, which eventually leads to the failure of support.

The methods of yieldable support technology mainly include Grille support [14, 15], Foam concrete [16-18], Bolt and anchorage cable's coupling yieldable support technology $[19,20]$, and Yielding arch [21, 22]. The support strategy allows a certain deformation of the surrounding rock to 
release the accumulated energy of the surrounding rock, while the support structure is always stable. According to the support method with rockbolt net spray, u-shaped shelf, and grouting, the surrounding rock of the tunnel is the main bearing structure, and the support body and surrounding rock are considered as the composites. The final intention is that the surrounding rock can show maximum self-bearing capacity [23]. The main method includes increasing the support density, grouting in the surrounding rock, increasing the length of anchor (cable), and increasing bolt (cable) pretightening force.

In the 1970s, the United States combined the expanding shell anchor with resin anchor and increased the diameter and strength of the anchor. At present, the prestress of bolt support in American coal mine roadway is generally about $100 \mathrm{kN}$, which has achieved good support effect. In England, the anchoring capacity of anchor bolt used in coal mine roadway support is about $500 \mathrm{kN}$. The roadway of Australian coal mine is supported by $60 \sim 70 \mathrm{kN}$ prestressed anchor bolt, and the support control is effectiveness. In 2005, China puts forward high-prestressed bolt and anchor cable support technology for deep coal mine roadway support, which greatly improved the support safety of coal mine roadway. However, in the field of deep tunnel support, there are few research studies in this field. Kang and Hongpu [24-26] studied the mechanical properties of highprestressed anchor rod and cable under the action of resin anchorage agent. The theory of high prestress and strong support is put forward for the deep difficult roadway of coal mine. They further developed a series of products, such as strong anchor (cable) and strong steel strip. The field application shows that the strategy can effectively control the deformation of the surrounding rock. Zhang et al. [27] put forward prestressed control methods such as high-performance pretension bolt, steel strand pretension truss, and M-type steel strip, aiming at the high-prestressed bolt support technology of coal mine roadway. Lin et al. [28] developed a large-scale test device for stress field of the anchor cable support and analyzed the distribution characteristics of the prestress with a single prestressed anchor cable. The experimental results show that the distribution of prestress field in space is similar to "pomegranate." Two compressive stress concentration zones are formed at both ends of the free section, and one tensile stress concentration zone is formed near the anchorage section. The distribution rule of the stress along the axis of bolt is related to the distance between the cable and the monitoring position. The macrodistribution characteristics of the stress field are basically the same with different pretensions, but the magnitude of the prestressing force at the same location will change.

This paper relies on the $\mathrm{Mu}$ Zhai-ling tunnel as the research object of the engineering experiment. The original support methods of the Mu Zhai-ling tunnel are as follows: $\Phi 42$ advance grouting small conduit $4500 \mathrm{~mm}$, spacing $400 \mathrm{~mm}$; I18 steel arch frame, spacing $500 \mathrm{~mm}$; and C25 shotcrete $250 \mathrm{~mm}$. However, according to the above support measures, during the advancing process of 2 \# inclined shaft of the Mu Zhai-ling tunnel, large-scale initial support failure occurred and the arch change rate reached $25 \%$, as shown in Figure 1. Therefore, it is necessary to explore a new support strategy to deal with the large cross-section area of inclined shaft and main tunnel.

\section{Engineering Geology}

The Mu Zhai-ling tunnel on Lanzhou-Hainan motorway is located in Dingxi city in China's Gansu province (Figure 2(a)). The project mainly includes two main tunnels and three inclined shafts (Figure 2(b)). The length of the $\mathrm{Mu}$ Zhai-ling left lane tunnel is $15,200 \mathrm{~m}$. The right of the $\mathrm{Mu}$ Zhai-ling left lane tunnel is $15,150 \mathrm{~m}$. The starting and ending points of the tunnel are located at AZK210 + 625 and AZK225 + 825, respectively.

The tunnel is located in the boundary zone of multiple plates, and the maximum buried depth of the tunnel is about $629.1 \mathrm{~m}$. The tunnel passes through three synclines and three anticlines. The crossing fault is mainly Meiwu-Xinsi fault. The strike of the fault is $100-115^{\circ}$ and north dipping and inclination is $30^{\circ}-70^{\circ}$, with the characteristics of compression and torsion. There are 12 secondary faults caused by the Meiwu-Xinsi fault, which are, respectively, f1 f12 (Figure 3 ). The fault is mainly distributed in northwest direction. Both inclined shaft and main tunnel used the drilling-and-blasting method and threestep construction technique for tunneling. The cross-section shape of the inclined shaft and main tunnel is the same, the design height of cross-section is $11.127 \mathrm{~m}$, and the width is $12.82 \mathrm{~m}$. The plane intersection angle between the inclined shaft and main tunnel is $90^{\circ}$ (Figure 4).

The method of hydraulic fracturing is used to measure the in situ stress. According to the relevant test data, three main stress interaction relations are obtained. The in situ stress is mainly tectonic stress, and the relationship between in situ stress and burial depth is fitted, as shown in Figure 5. The maximum horizontal principal stress directions measured by hydraulic fracturing method are near NE39.6 and NE34. $1^{\circ}$. The direction of the maximum horizontal principal stress is nearly parallel to the direction of the main tunnel excavation.

The entrance and exit sections of the tunnel are shallow buried sections. It is mainly composed of slope loess soil, gravel soil, paleogene conglomerate, and permian strongly weathered carbonaceous slate and sandstone. The stratum of this section is complex. The joints and fissures are developed, and the integrity of the surrounding rock is poor, and it is easy to be weathered and destroyed when encountering air or water after excavation. The tunnel intersection of the research object is located in the middle of the line with a buried depth of $510 \mathrm{~m}$. The main lithology is thin-layer carbonaceous slate. According to the relevant GSI value standard, combined with the actual engineering geological conditions, the approximate value of GSI is 35. As shown in Figure 6, it is the surrounding rock condition of the tunnel face. According to the field investigation, the dip angle of the surrounding rock changes greatly and the dominant joint angle is between $30^{\circ}$ and $85^{\circ}$.The surrounding rock of the tunnel is in thin bed structure, and the thickness of slate is $5 \mathrm{~cm}-30 \mathrm{~cm}$. 

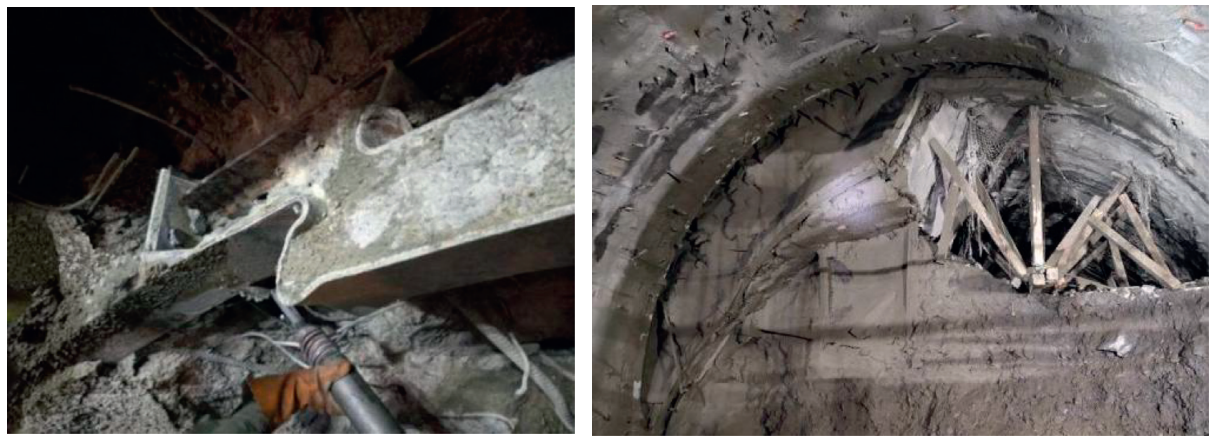

FIGURE 1: Splitting of primary lining and exceeding clearance limit.
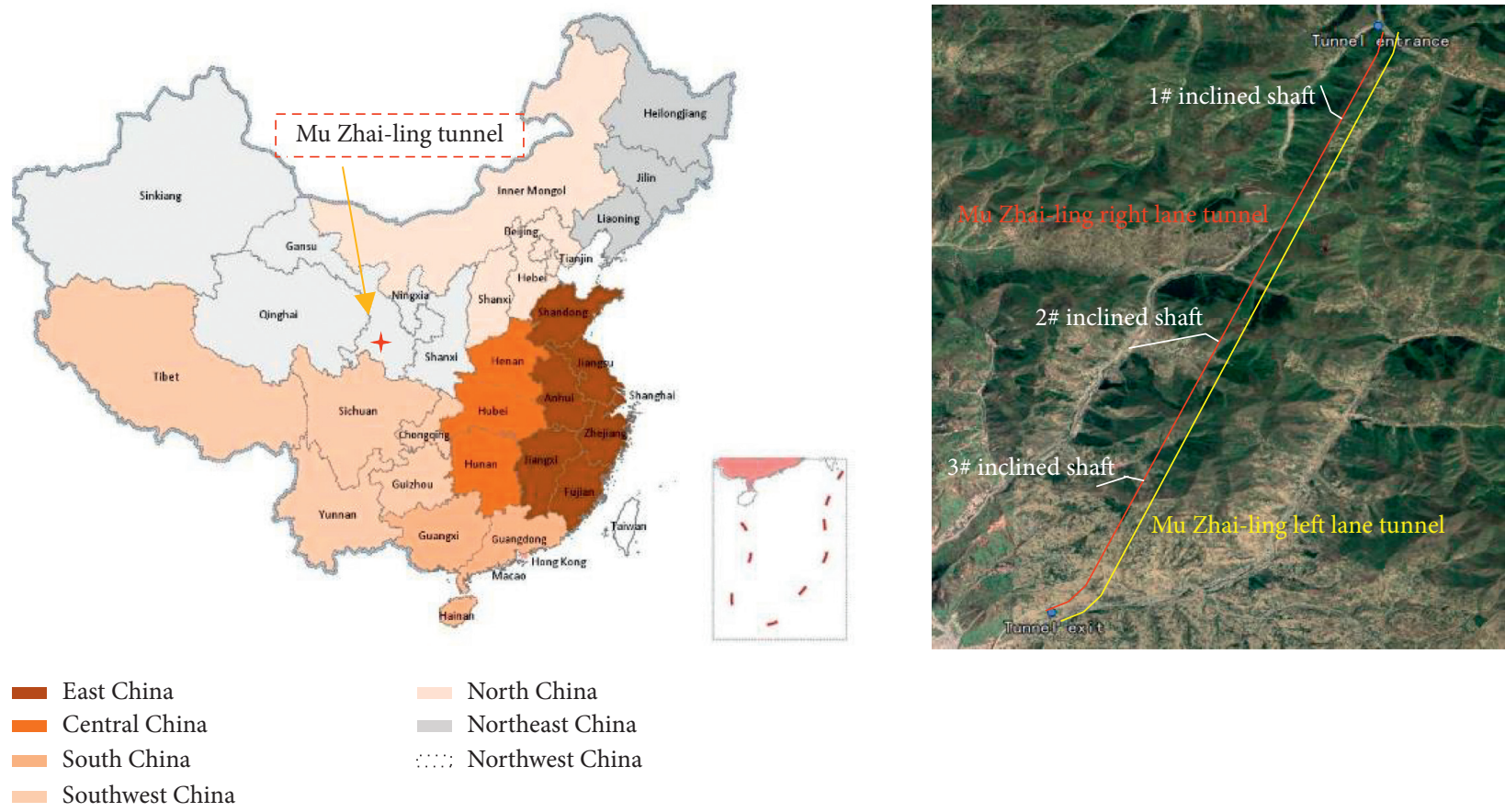

Figure 2: (a) Location of the Mu Zhai-ling tunnel, Gansu, China. (b) Plane view of the tunnel.

\section{Countermeasures for Damage Mitigation with High-Pretension Cable}

3.1. Mechanical Model of Tunnel Surrounding Rock Structure. After the excavation of the tunnel, the original rock stress state is destroyed, the surrounding rock has uneven displacement, and the internal stress state of the rock changes, forming a secondary stress field. When the stress is redistributed and stabilized, there will be a tangential compression area similar to the arch structure above the excavation chamber, which is called pressure arch. The rock mass in the pressure arch bears the load of itself and the upper rock mass. Therefore, in order to effectively restrain the large deformation of the surrounding rock, the bearing capacity of the surrounding rock bearing arch should be strengthened. Therefore, build the model, as shown in Figure 7. In this paper, it is considered that the surrounding rock obeys the D-P [29-31] (Drucker-Prager) criterion under the action of limit equilibrium, as shown in formula (1)-(5). The highpretension anchor cable can effectively improve the stress state of the surrounding rock in the pressure arch, as well as the cohesion and internal friction angle of the surrounding rock in the pressure arch:

$$
\begin{aligned}
\sqrt{J_{2}}-\alpha I_{1}-k=0, \\
\alpha=\frac{2 \sin \varphi}{\sqrt{3}(3-\sin \varphi)}, \\
k=\frac{6 C \cos \varphi}{\sqrt{3}(3-\sin \varphi)}, \\
I_{1}=\sigma_{1}+\sigma_{2}+\sigma_{3}, \\
J_{2}=\frac{1}{6} \sqrt{\left(\sigma_{1}-\sigma_{2}\right)^{2}+\left(\sigma_{2}-\sigma_{3}\right)^{2}+\left(\sigma_{3}-\sigma_{1}\right)^{2}} .
\end{aligned}
$$




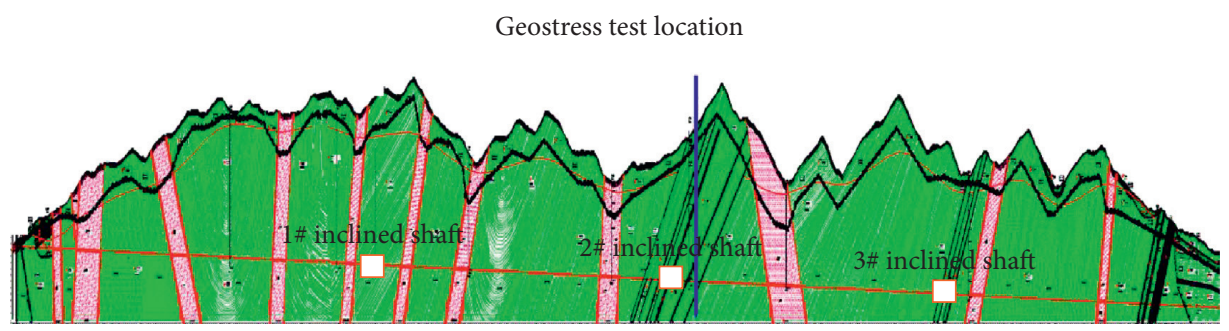

FIGURE 3: Geostress test location and geological cross-section along the tunnel route.

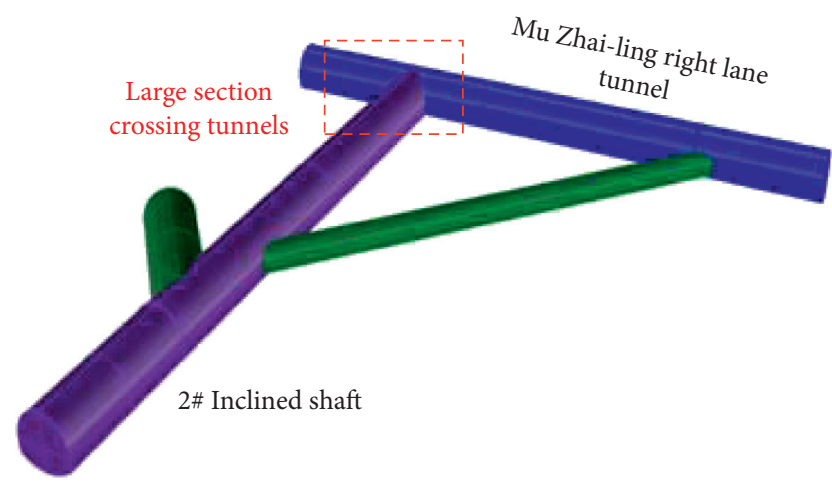

FIgURE 4: Layout of No. 2 inclined shaft of the Mu Zhai-ling tunnel.

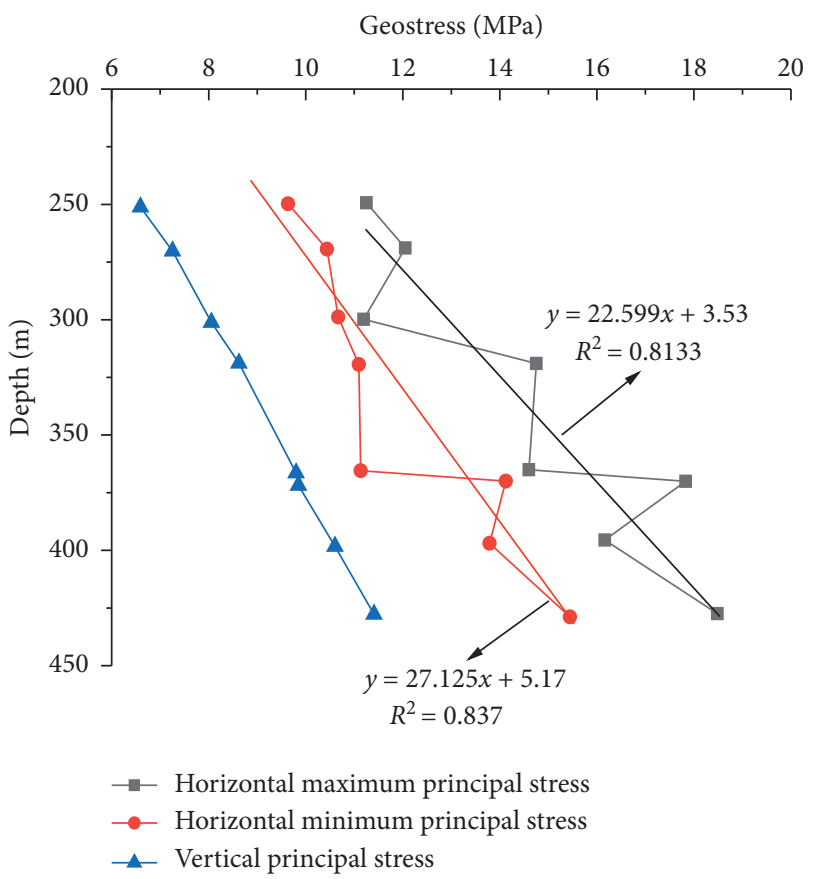

FIGURE 5: Map of principal stress variation with depth in the $\mathrm{Mu}$ Zhai-ling tunnel area.

where $\varphi$ and $C$ are the angle of internal friction and cohesion, $\sigma_{1}$ is the maximum principal stress, $\sigma_{2}$ is the intermediate principal stress, and $\sigma_{3}$ is the minimum principal stress.

When the stress state of any point of the surrounding rock in the pressure arch meets formula (10), it will enter the plastic failure state. After the excavation of the tunnel, the stress-arch side wall is affected by the pretightening force, and the pretightening force of the anchor cable exerts the stress on the surrounding rock is $\sigma_{3}$. The stress parallel to the tunnel direction is $\sigma_{2}$, so the maximum stress of the pressure arch is $\sigma_{1}$.

Assuming $\sigma_{2}=1, C=0.6$, and $\varphi=25^{\circ}$, when $\sigma_{3}$ increases from $0 \mathrm{MPa}$ to $7 \mathrm{MPa}$, the change of the maximum bearing capacity $\sigma_{1}$ is shown in Figure 8. Assuming $\sigma_{3}=3, \sigma_{2}=1$, and $C=0.6$, when $\varphi$ is increased from $5^{\circ}$ to $45^{\circ}$, the change of the maximum bearing capacity $\sigma_{1}$ is shown in Figure 9. Assuming $\sigma_{3}=3, \sigma_{2}=1$, and $\varphi=25^{\circ}$, when $C$ increases from $0 \mathrm{MPa}$ to $6 \mathrm{MPa}$, the change of the maximum bearing capacity $\sigma_{1}$ is shown in Figure 10. The results show that, with the increase of preload, internal friction angle, and cohesion, the bearing capacity of the pressure arch is significantly improved.

\subsection{Pretension Cable-Mesh-Shotcrete + Steel Arch Combined} Support Technology. According to the above analysis and the three-step construction process, a combined support scheme of "high-pretension cable + mesh + shotcrete + steel arch" is proposed, within $20 \mathrm{~m}$ of the intersection point, as shown in Figure 11.

Long anchor cable: the pretightening force is $350 \mathrm{kN}$, the diameter of steel strand is $21.8 \mathrm{~mm}$, the length is $10300 \mathrm{~mm}$, the strength grade is $1860 \mathrm{MPa}$, the drilling diameter is $32 \mathrm{~mm}$, and the row spacing between anchor cables is $1000 \mathrm{~mm} \times 1200 \mathrm{~mm}$. Short anchor cable: the pretightening force is $35 \mathrm{t}$, the diameter of steel strand is $21.8 \mathrm{~mm}$, the length is $5300 \mathrm{~mm}$, and the row distance between anchor cables is $1000 \mathrm{~mm} \times 1200 \mathrm{~mm}$. W-type steel strip: $280 \mathrm{~mm}$ wide, $2.8 \mathrm{~mm}$ thick, and Q235 material. As shown in Figures 12-14, it is the support scheme of the inclined shaft, main tunnel, and intersection, and the support mode of the inclined shaft and main tunnel is the same.

(1) "Pretension cable-mesh-shotcrete" initiative support: the minimum pretightening force of the cable is no less than $350 \mathrm{kN}$. The cable is designed to be installed with a $3000 \mathrm{~mm}$ steel strip and mesh polymer. As shown in Figure 15, $\Phi 21.8 \mathrm{~mm} \times 10300 \mathrm{~mm}$ high-strength cables are installed with row spacing and column spacing of $1200 \mathrm{~mm} \times 1000 \mathrm{~mm}$. $\Phi 21.8 \mathrm{~mm} \times 5300 \mathrm{~mm}$ highstrength cables are installed with row spacing and column spacing of $1200 \mathrm{~mm} \times 1000 \mathrm{~mm}$. 

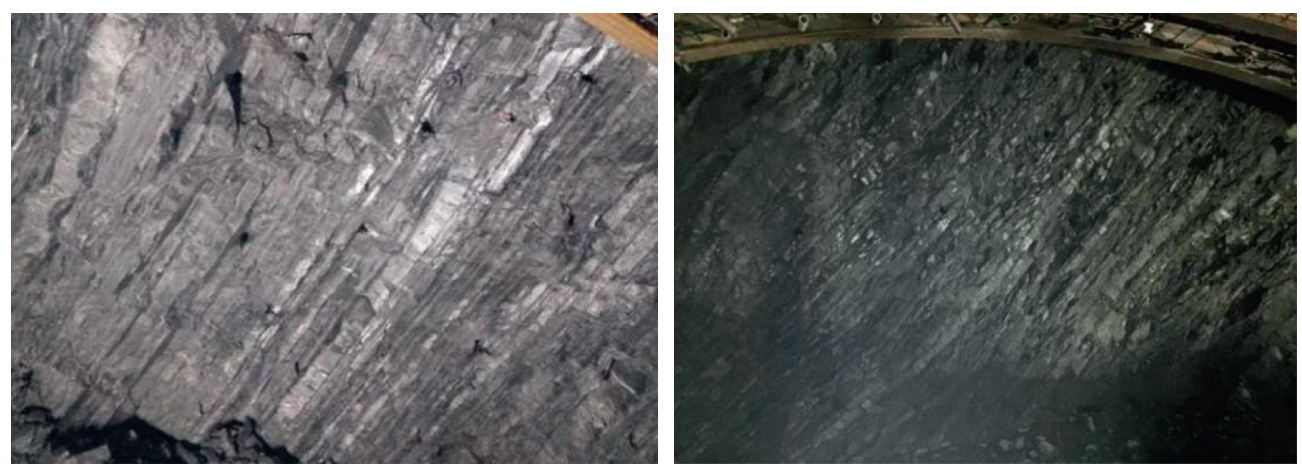

FIGURE 6: surrounding rock of the tunnel face.

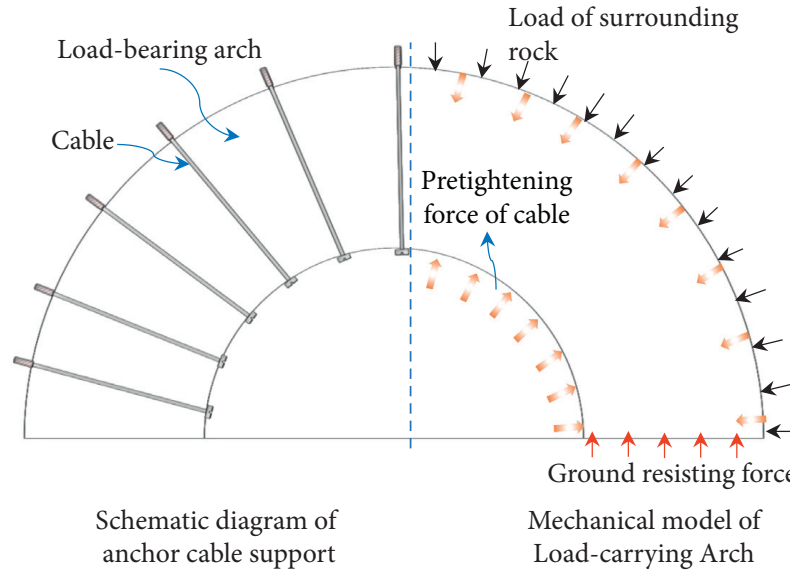

Figure 7: Mechanical model of bearing structure under the action of the prestressed cable.

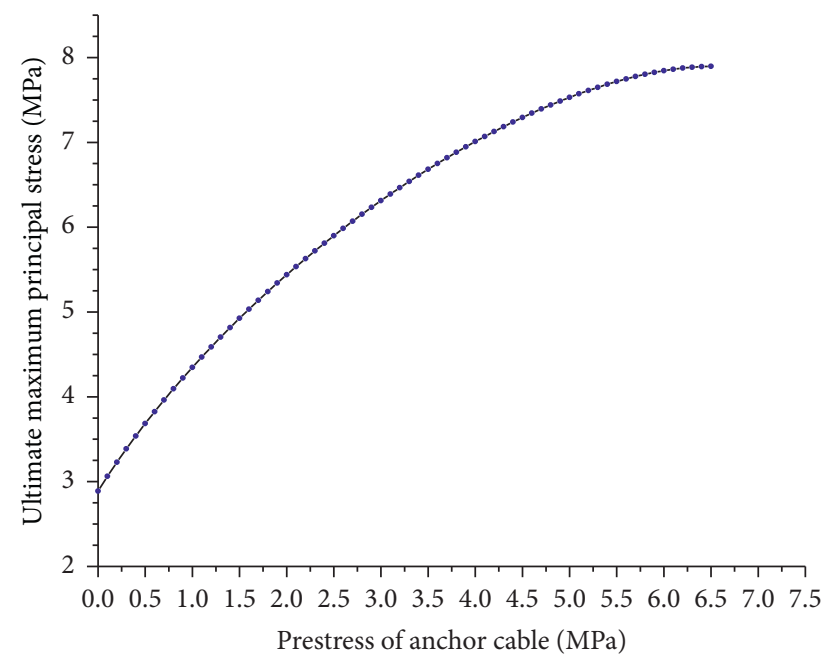

FIgURE 8: The change of the maximum bearing capacity with the pretension of the anchor cable.

(2) "Strengthened support with 18a I-steel and shotcrete": according to the measured position, each section of steel frame is connected by bolts. In order

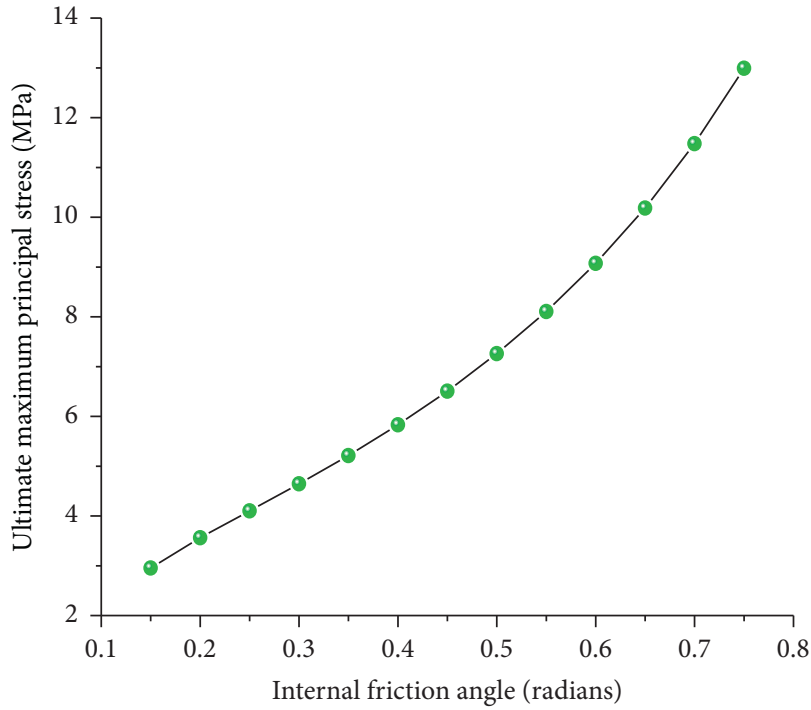

FIGURE 9: The change of the maximum bearing capacity with the internal friction angle.

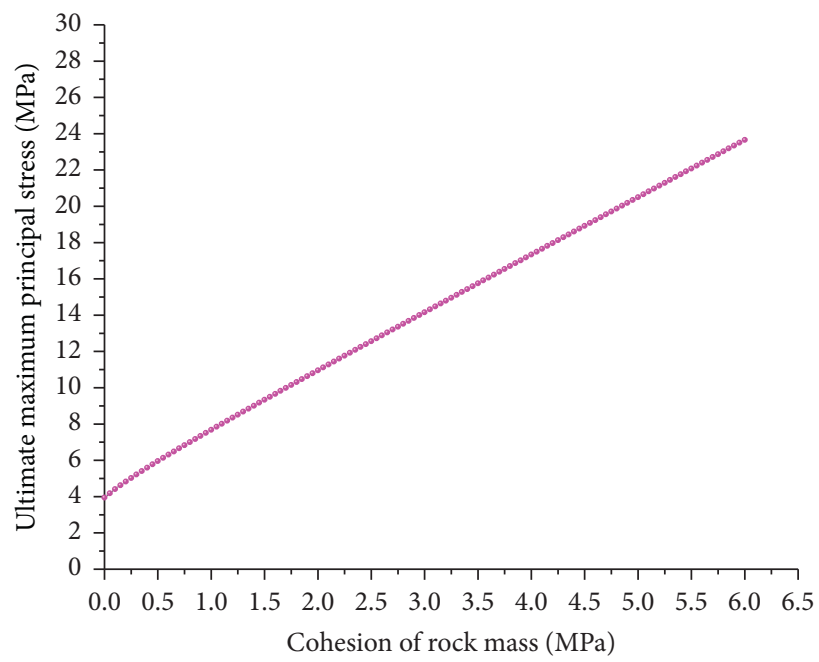

FIgURE 10: The change of the maximum bearing capacity with cohesion of rock mass. 


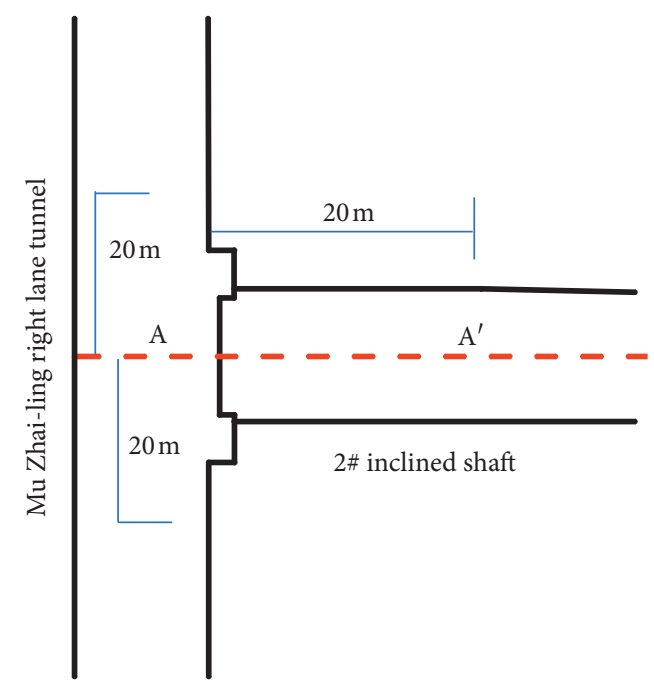

FIgURE 11: Tunnel intersection plan.

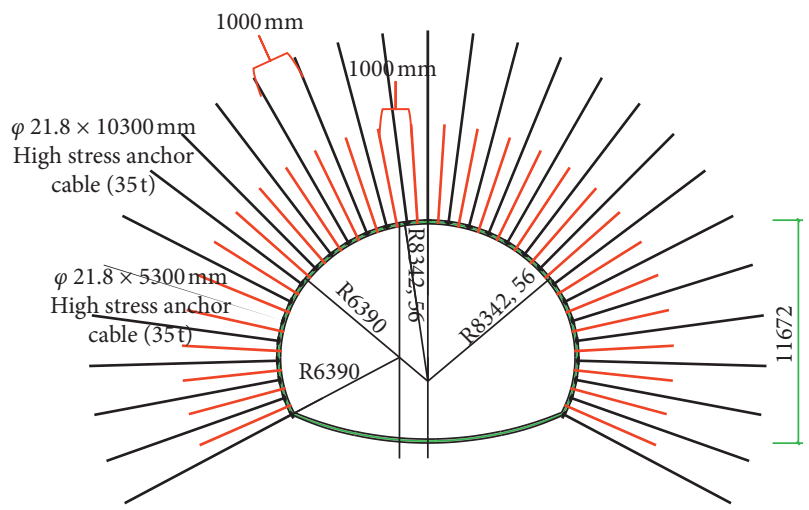

FIGURE 12: Inclined shaft and main tunnel support scheme layout.

to ensure that each section of the steel frame is placed on a stable foundation before the full-ring closure, the virtual slag and sundries at the bottom of each section of the steel frame shall be removed before installation. At the same time, four $\Phi 42$ lock foot anchor pipes are installed on each side to lock it, and the back of the steel frame is filled with shotcrete. The longitudinal connection of the steel frame is connected with steel bars, with a circumferential spacing of $0.6 \mathrm{~m}$.

As shown in Figure 15, the construction process mainly includes tunnel excavation, anchor cable drilling, installation of the cable, pretension tension, mesh and steel strip installation, steel arch, and shotcrete installation. After the deformation of the surrounding rock is stable, the second lining construction shall be carried out.

\section{Numerical Model Establishment}

4.1. Establishment of Numerical Calculation Model. A numerical model of the tunnel intersection is created by 3DEC (3 Dimension Distinct Element Code) software. In order to consider the failure characteristics of the surrounding rock under three-dimensional stress state, the D-P (Drucker-Prager) constitutive model is selected. The Coulomb friction law can realize the sliding or opening of joints, which is very suitable for simulating the failure process of the surrounding rock.

In this paper, the method of equivalent ubiquitous joint with dominant joint is proposed. The lithology of the surrounding rock is mainly carbonaceous slate, and under the long geological structure, the rock mass is distributed with complex and variable joints. In the process of numerical simulation, it is obviously impossible to consider all joints. As shown in Figure 16, the distribution of surrounding rock joints is generalized, and it is obvious that there are dominant joint groups and other joints. Other joints (except the dominant joints) can be regarded as isotropic macroscopically, and the method of uniform joint arrangement is used for continuity medium equivalence. After the joints are evenly arranged, the dominant joints are divided. The equivalent ubiquitous joint model with the dominant joint group is finally obtained.

As shown in Figure 17, the tunnel-intersection numerical model is established, which includes the tunnel section, anchor cable, initial support and second-lining concrete, and uniform joint and dominant joint arrangements. The buried depth at the intersection is $510 \mathrm{~m}$. According to the in situ stress test results, the vertical in situ stress is $12.5 \mathrm{MPa}$, the maximum horizontal stress is $21 \mathrm{MPa}$ (parallel to the main tunnel direction), and the minimum horizontal stress is 12.5 $\mathrm{MPa}$ (perpendicular to the main tunnel direction). In order to fully consider the boundary effect, the model length $\times$ width $\times$ height $=120 \mathrm{~m} \times 80 \mathrm{~m} \times 50 \mathrm{~m}$, containing 246,400 blocks.

4.2. Block Yield Model. Under the action of the highprestressed support system, this paper believes that the rock in the range of influence of the support is under stress in three directions. The failure of the rock is related to the three principal stresses and their ratios, so the Drucker-Prager elastoplastic constitutive model is selected to achieve the failure of the block. The failure criterion is represented in the plane $(\sigma, \tau)$ as illustrated in Figure 18 (as shown in equations (10)-(14)). The failure envelope is defined by the Drucker-Prager yield function from point $A$ to $B$, and the tension yield function from $B$ to $\mathrm{C}$.

4.3. Contact Model. In 3DEC discrete element numerical simulation, Coulomb slip constitutive model [32, 33] is widely used in geotechnical engineering. The joint model can fully represent the shear failure, tensile failure, and compression deformation of jointed rock mass. The tensile resistance of joints is

$$
T_{\max }=-T A_{c} .
$$

where $T$ is the input parameter that represents the joint tensile strength and $A_{c}$ represents the area of the subcontact. 


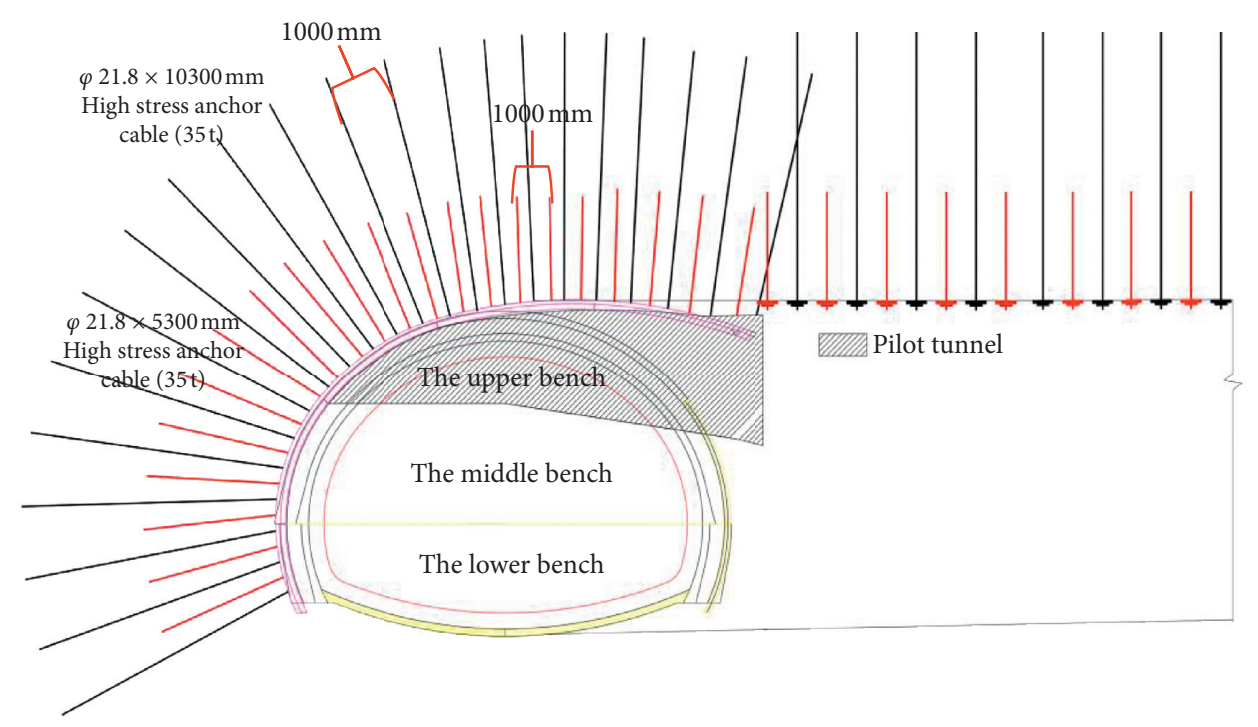

FIgURE 13: Cross-section of the intersection support scheme layout (A-A').

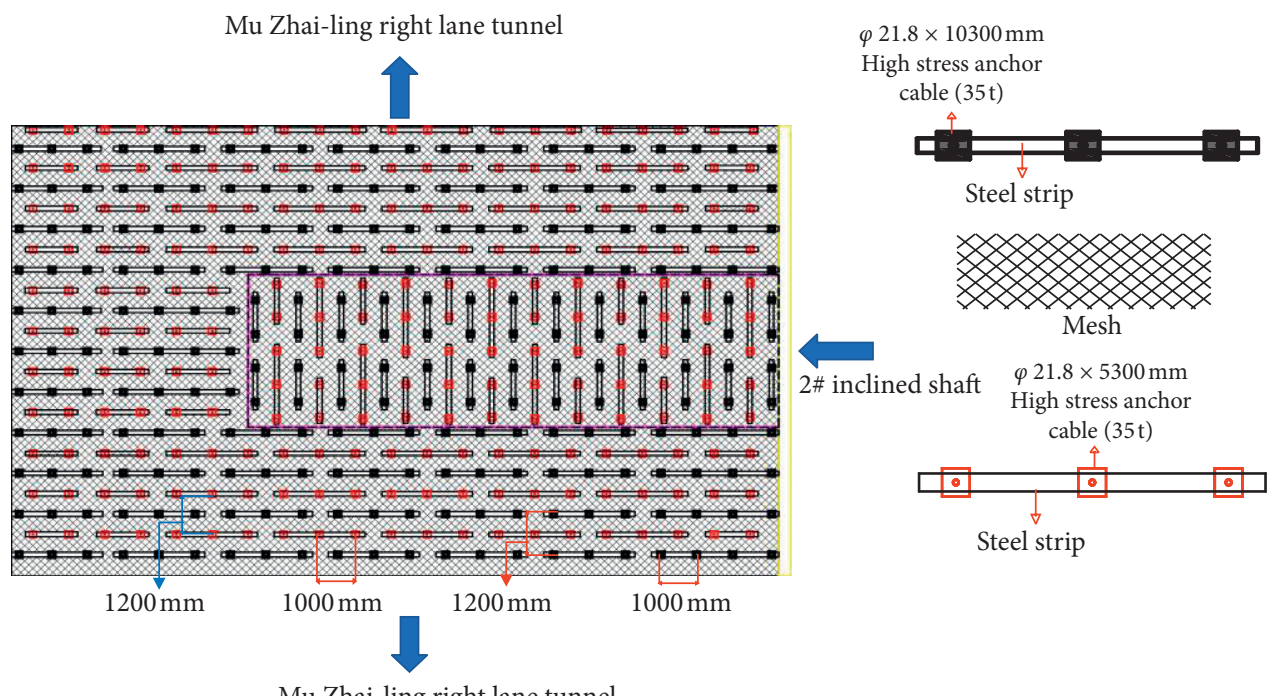

Mu Zhai-ling right lane tunnel

FIgURe 14: Plane expansion diagram of the tunnel support.

The expression of the maximum shear stress that the joint can bear is

$$
F_{\max }^{s}=c A_{c}+F^{n} \tan \phi
$$

where $c$ and $\phi$ represent joint cohesion and internal friction angles, respectively, and $F^{n}$ represents normal stress acting on the joint.

Under the action of normal stress, joints will produce compression deformation, which is related to the normal stiffness of joints. In this paper, the compression failure of the block obeys the D-P criterion. When the joint is damaged, the internal friction angle and tensile strength of the joint surface will be classified as 0 .

4.4. Physical and Numerical Experimental Analysis of Conventional Triaxial Compression. In order to accurately analyze the mechanical properties of carbonaceous slate and provide parameter basis for theoretical analysis and numerical calculation, the mechanical characteristics of cylindrical specimens under different confining pressures are analyzed by using rock mechanics test system. Using the method of numerical simulation, the development law of stress-strain relationship is analyzed. Compared with the experimental data, the reliability of the constitutive model in numerical simulation is verified. The size of the sample is $50 \mathrm{~mm} \times 100 \mathrm{~mm}$ cylinder. In this loading process, the displacement control mode is adopted, and the displacement rate is $0.001 \mathrm{~mm} / \mathrm{s}$. The confining pressure range is 0-30 MPa. The total stress-strain curves under different confining pressures are shown in Figure 19. The experimental results show that, with the increase of confining pressure, the overall trend of compressive strength and the plastic deformation after the peak value are increased. 


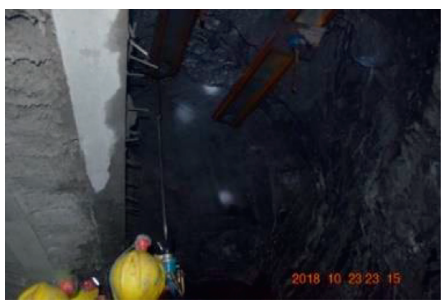

Drilling of cable

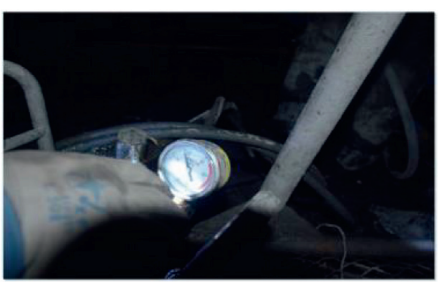

Control console of tensioning machine

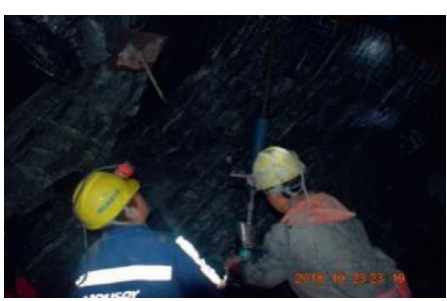

Install the cable

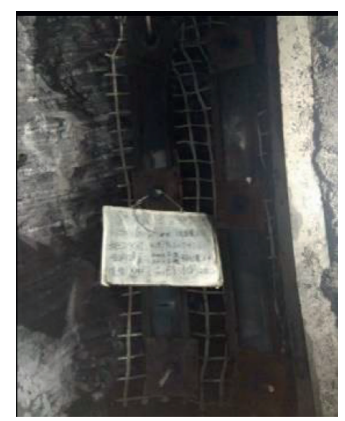

Applied mesh and steel strip

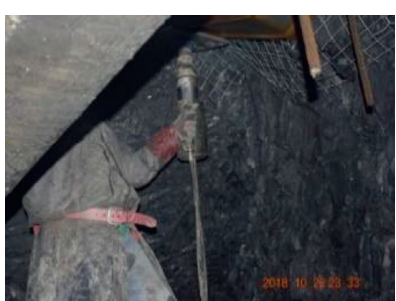

Pretightening force of the cable

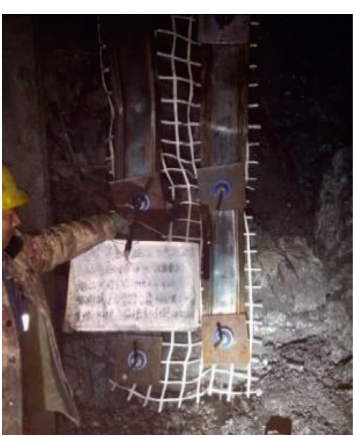

Cable installation completed

FIGURE 15: Pretension cable-mesh installation process.

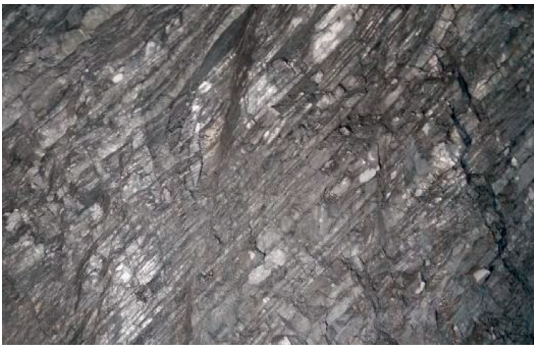

(a)

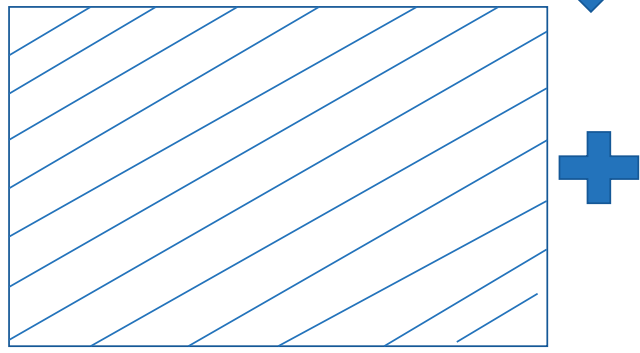

(c)

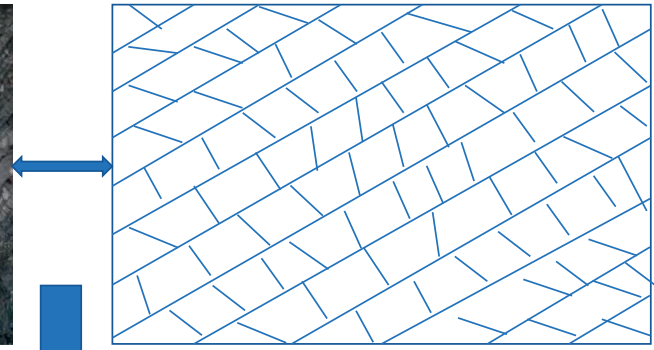

(b)

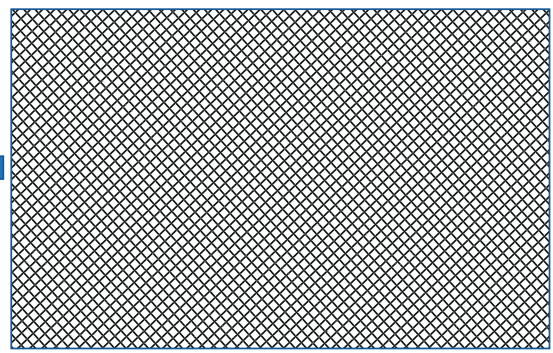

(d)

FIGURE 16: Modeling method of equivalent joints with dominant joints: (a) characteristics of the surrounding rock, (b) generalization of joint distribution, (c) dominant joints, and (d) equivalent ubiquitous joints.

As shown in Figure 20, a numerical model of rock triaxial experiment is established in this paper, which includes loading plate; surrounding rock area, and rock sample bin. The size of the rock sample in the similar simulation is the same as that in the conventional physical experiment, and the joint with the length of $0.5 \mathrm{~mm}$ is evenly distributed. The block constitutive model is the D-P model, and the joint constitutive model is the Coulomb slip model. Through rock mechanics experiments and repeated attempts, the parameter values are shown in
Table 1 . The numerical results show that the bearing capacity of the specimen is positively related to the surrounding rock pressure. The simulation results are in good agreement with the test results, as shown in Figure 21.

4.5. Engineering Rock Mass Parameter Value. The selection of engineering rock mass mechanical parameters just relies on the experimental data and cannot meet the 


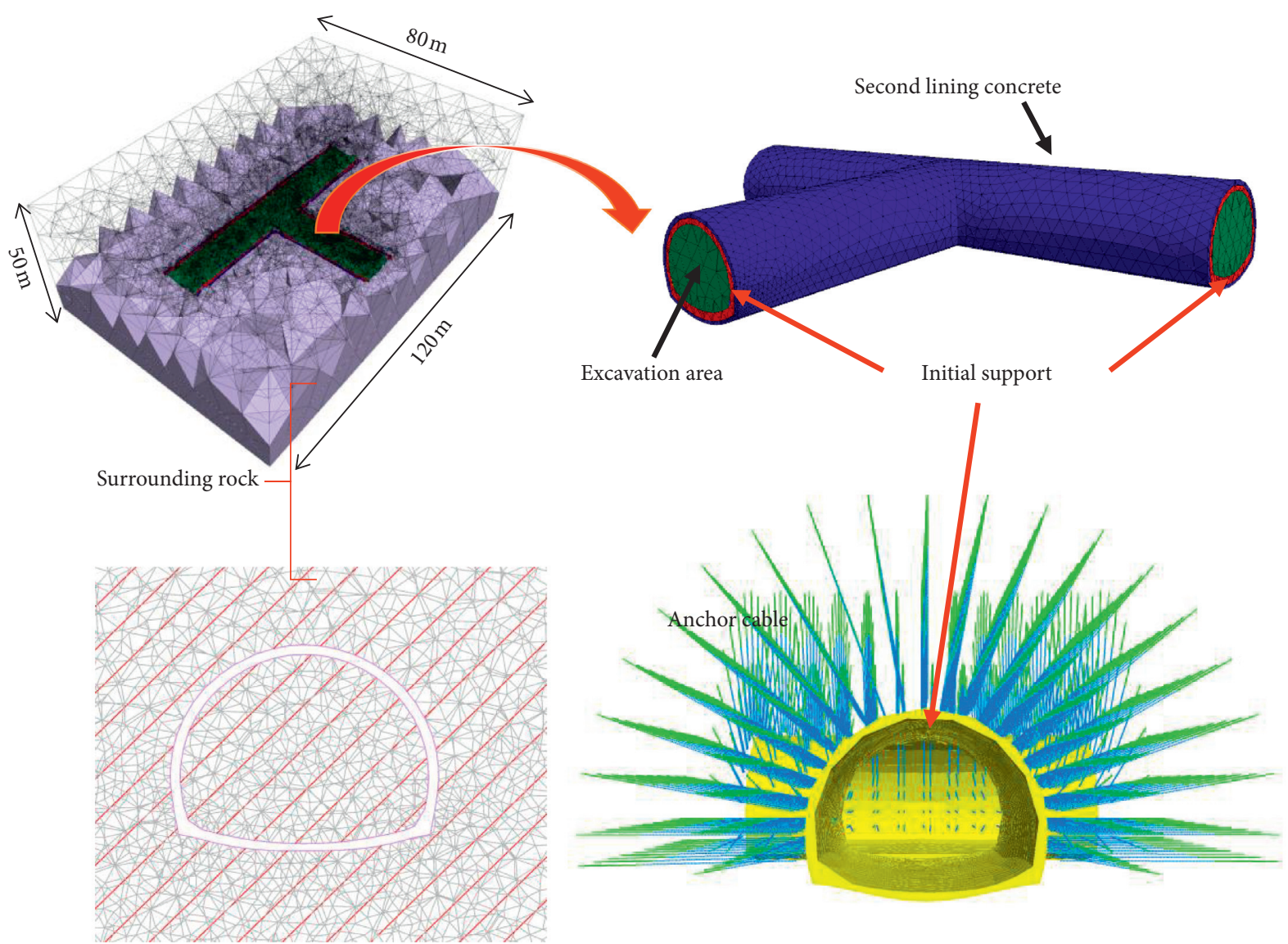

Figure 17: Numerical calculation model.

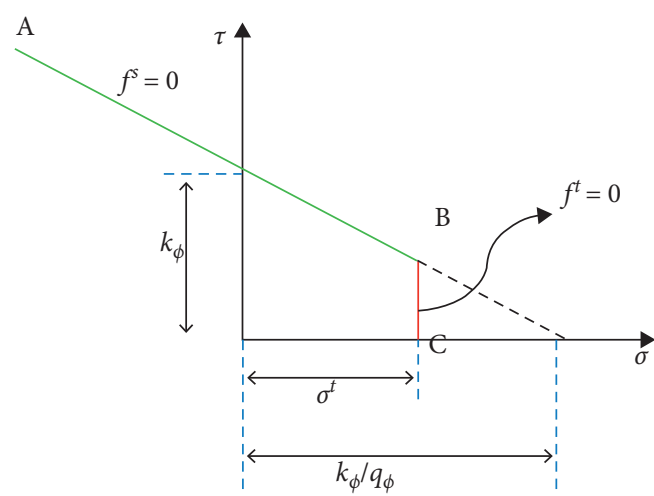

Figure 18: The Drucker-Prager failure criterion.

requirements. The selection of parameters in numerical calculation plays an important role in the calculation results. The selection of parameters not only needs to consider the solid properties, such as rock strength, but also needs to consider the occurrence environment and structural characteristics of rock mass. Hoek established a method of rock mass strength conversion based on GSI geological classification index, which was converted by the following formulas (8)-(12) [34]:

$$
\begin{aligned}
\frac{\mathrm{E}_{\mathrm{rm}}}{E_{i}} & =\left(0.02+\frac{1-\mathrm{D} / 2}{1+e^{(60+15 D-\mathrm{GSI}) / 11}}\right) \\
\sigma_{\mathrm{cmass}} & =\sigma_{c i} \frac{\left(m_{b}+4 s-a\left(m_{b}-8 s\right)\right)}{2(1+a)(2+a)}\left(\frac{m_{b}}{4+s}\right)^{\mathrm{as}-1}, \\
m_{b} & =m_{i} \exp \left(\frac{\mathrm{GSI}-100}{28-14 D}\right), \\
\mathrm{s} & =\exp \left(\frac{\mathrm{GSI}-100}{9-3 D}\right), \\
\mathrm{a} & =\frac{1}{2}+\frac{1}{6}\left(e^{-(G S I / 15)}-e^{-(20 / 3)}\right),
\end{aligned}
$$

In the formula, $\mathrm{E}_{\mathrm{rm}}$ is the elastic modulus of rock mass, $\sigma_{\text {cmass }}$ is the uniaxial compressive strength of rock mass, GSI is the geological strength index, $E_{i}$ is the deformation modulus of rock, $m_{i}$ is Hoek-Brown strength parameter of the intact rock block, $\sigma_{c i}$ is the uniaxial compressive strength of intact rock, and $D$ is the damage coefficient of rock mass.

According to the principle of joint parameter selection in the literature "Itasca Consulting Group, Inc. 3DEC User Manual and Itasca Consulting Group, Inc.: 


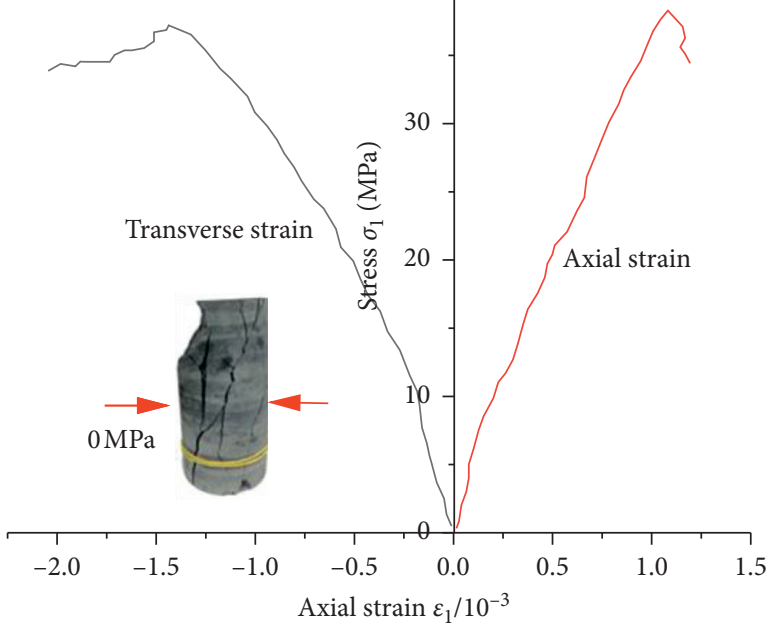

(a)

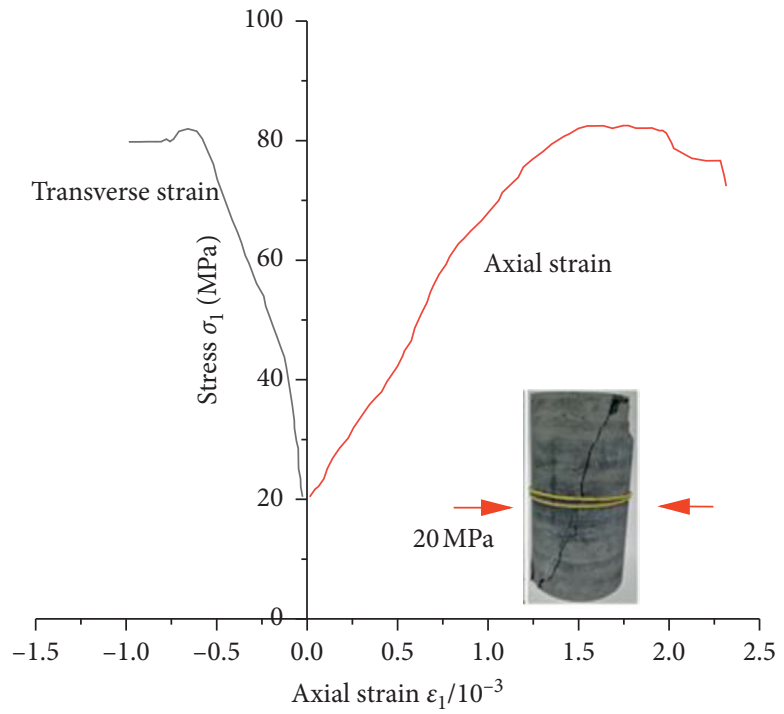

(c)

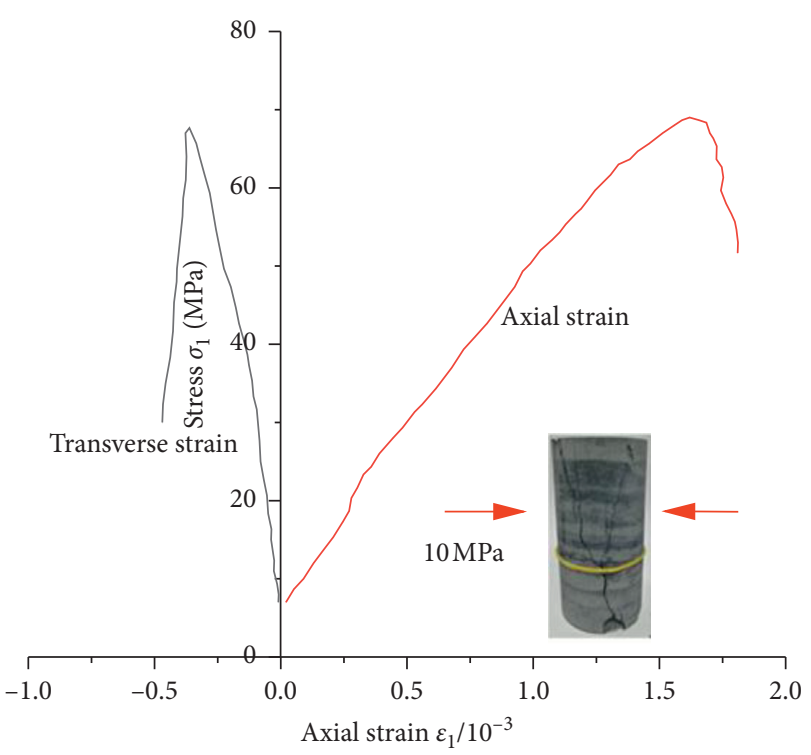

(b)

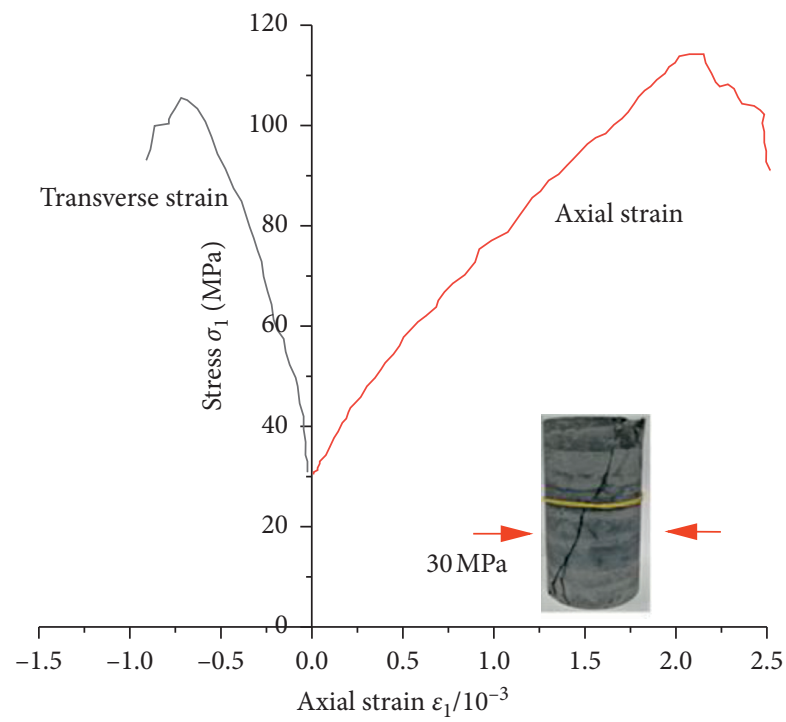

(d)

FIGURE 19: Stress-strain curves of slate on triaxial compression tests under different confining pressures: (a) $0 \mathrm{MPa}$, (b) $10 \mathrm{MPa}$, (c) $20 \mathrm{MPa}$, and (d) $30 \mathrm{MPa}$.

Minneapolis, MN, USA, 2016," the joint uniform distribution modeling is carried out, such as formulas (13)-(16), and the characteristic element is selected $\Delta z=0.8 \mathrm{~m}$ :

$$
\begin{aligned}
K & =\frac{E}{3(1-2 \mu)}, \\
G & =\frac{E}{2(1+\mu)}, \\
K_{n} & =10\left[\frac{K+3 / 4 G}{\Delta z_{\min }}\right],
\end{aligned}
$$

$$
K_{s}=0.4 K_{n}
$$

According to the characteristics of laboratory test and field engineering, the GSI value is 35 , the Hoek-Brown strength parameter $m_{i}$ of the intact rock mass is 10 , the uniaxial compressive strength of the rock block is $40 \mathrm{MPa}$, the elastic modulus of the rock block is $33 \mathrm{GPa}$, Poisson's ratio is 0.25 , and the damage coefficient of the rock is 0.5 . According to the above calculation formula and the results of relevant parameters, the mechanical parameters in the numerical simulation are obtained, as shown in Table 2. After multiple inversion analysis, combined with the field-measured deformation data of the surrounding rock, the normal stiffness of the dominant joint is $2 \mathrm{GPa}$, the 


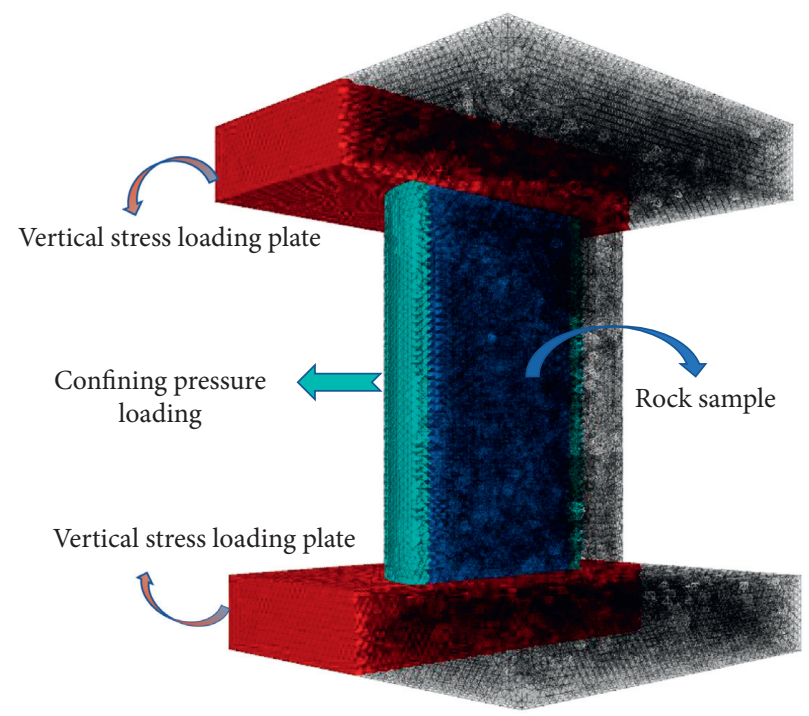

FIGURE 20: Numerical experiment model.

TABLE 1: Parameters for the rock.

\begin{tabular}{lcccccccccc}
\hline & \multicolumn{4}{c}{ Block properties } & \multicolumn{4}{c}{ Contact properties } \\
Density $\left(\mathrm{kg} / \mathrm{m}^{3}\right)$ & $\mathrm{K}(\mathrm{GPa})$ & $\mathrm{G}(\mathrm{GPa})$ & $\mathrm{C}^{b}(\mathrm{MPa})$ & $\varphi^{b}$ & $\sigma^{b}{ }_{t}(\mathrm{MPa})$ & $\mathrm{K}^{\mathrm{n}}(\mathrm{GPa}$ & $\mathrm{k}^{\mathrm{s}}(\mathrm{GPa})$ & $\mathrm{C}^{j}(\mathrm{MPa})$ & $\varphi^{j}$ & $\sigma_{t}^{j}(\mathrm{MPa})$ \\
\hline 2420 & 12.3 & 8.1 & 13.6 & 32 & 2.30 & 87.31 & 33.11 & 1.55 & 31 & 1.34 \\
\hline
\end{tabular}

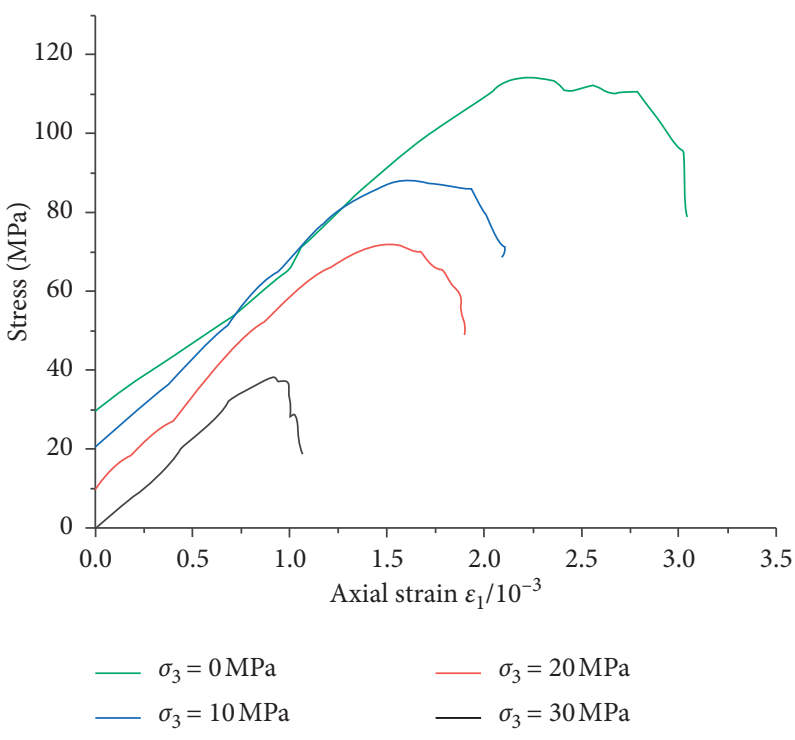

FIgURE 21: Stress-strain curves of slate.

shear stiffness is $1 \mathrm{GPa}$, the cohesion is $0.9 \mathrm{MPa}$, the internal friction angle is $25^{\circ}$, and the tensile strength is $0.5 \mathrm{MPa}$.

\section{Numerical Analysis of Therapeutic Effects under Different Pretensions}

5.1. Diffusion Characteristics of Prestress in the Surrounding Rock. In this part of the study, in order to better understand the diffusion characteristics of prestress in the surrounding rock and eliminate the interference of in situ stress, only the application of prestress is considered. The $5 \mathrm{~m}$ anchor cable embedment length is $1 \mathrm{~m}$. The $10 \mathrm{~m}$ anchor cable embedment length is $2 \mathrm{~m}$. In the process of prestress application, the tensile stress of the anchor cable is transferred from the end to the depth and finally reaches the equilibrium state. As shown in Figure 22, the stress characteristics of the anchor cable near the anchorage section under different preloads. The axial stress of the anchor cable shows that, with the increase of pretension, the tensile stress increases linearly in the free segment part. The 
TABLE 2: . Mechanical parameters of carbonaceous slate.

\begin{tabular}{|c|c|c|c|c|c|c|c|c|c|c|c|}
\hline \multirow{2}{*}{ Lithology } & \multicolumn{6}{|c|}{ Rock mass parameters } & \multicolumn{5}{|c|}{ Homogeneous joint parameters } \\
\hline & Density $\left(\mathrm{kg} / \mathrm{m}^{3}\right)$ & $\mathrm{K}(\mathrm{GPa})$ & $\mathrm{G}(\mathrm{GPa})$ & $C^{b}(\mathrm{MPa}$ & $\varphi^{b}$ & $\sigma_{t}^{b}(\mathrm{MPa})$ & $\mathrm{K}^{\mathrm{n}}(\mathrm{GPa})$ & $\mathrm{k}^{\mathrm{s}}(\mathrm{GPa})$ & $C^{j}(\mathrm{MPa})$ & $\varphi^{j}$ & $\sigma_{t}^{j}(\mathrm{MPa})$ \\
\hline Carbonaceous slate & 2500 & 0.56 & 0.27 & 1.68 & 23 & 0.6 & 9.53 & 0.38 & 3.75 & 29 & 3.45 \\
\hline
\end{tabular}

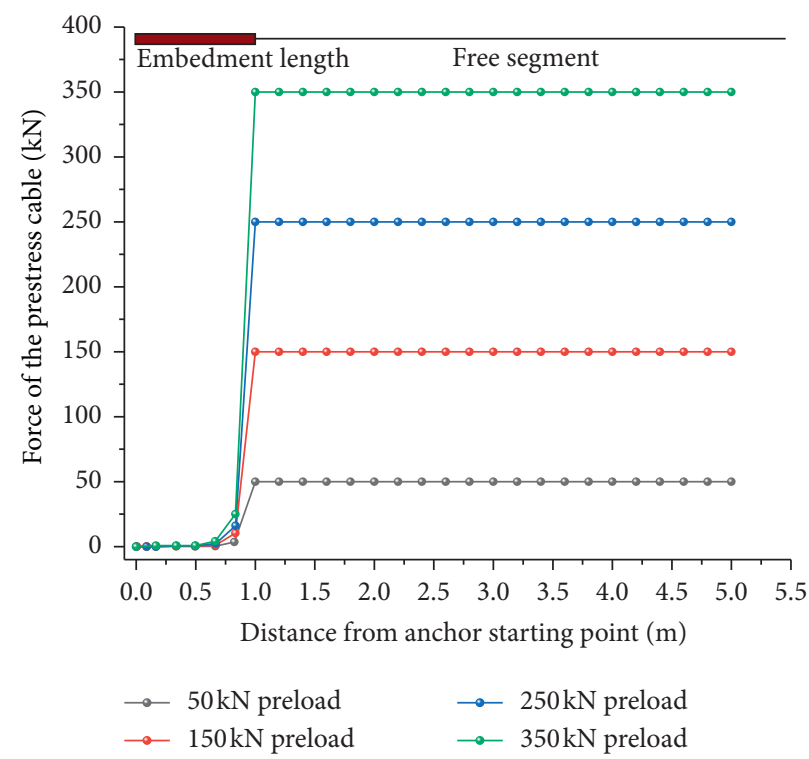

Figure 22: The stress distribution curve of the prestressed cable.

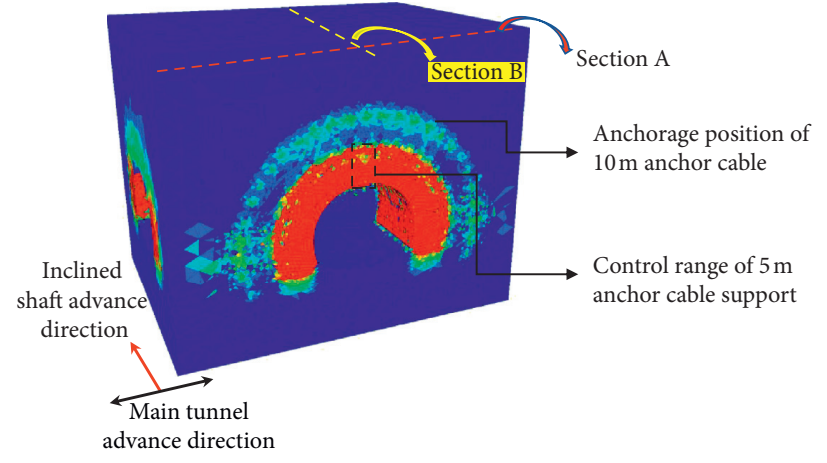

FIGURE 23: Compressive stress distribution contour with the pretension cable.

tensile stress of the anchor cable decreases gradually along the direction of hole bottom in the embedment part. Under the action of $350 \mathrm{kN}$ preload, the influence area of the embedment section is $0.5 \mathrm{~m}$, so the length of the anchorage section must not be less than $0.5 \mathrm{~m}$ in the construction, and the safety factor needs to be considered.

As shown in Figures 23 and 24, it is the prestressed diffusion effect under the combined action of $5 \mathrm{~m}$ and $10 \mathrm{~m}$ anchor cables. The prestress of the anchor cable is $350 \mathrm{kN}$. The anchor cables are evenly distributed (the circumferential spacing is $1 \mathrm{~m}$ and the longitudinal spacing is $1.2 \mathrm{~m}$ ). Because of the combination of long and short anchor cables, the support resistance in the support area is significantly increased. Under the action of high pretension, long and short anchor cables can produce better active control effect on the surrounding rock. The effective prestressing force is effectively diffused in the range of $10 \mathrm{~m}$, and the effective stresses produced by the long and short anchor cables are superimposed on each other, forming the prestressed expansion area of the double-arch prestressing force. For the low-arch formed by $5 \mathrm{~m}$ prestressed anchor cable, the prestress diffusion in the arch is relatively uniform, and the prestress value is about 3.3 $\mathrm{MPa}$. Compared with the low-arch, the high-arch formed by $10 \mathrm{~m}$ prestressed anchor cable has poor uniformity of prestress diffusion and the prestress value near the anchorage position is $2-3 \mathrm{MPa}$.

5.2. Deformation Characteristics of the Surrounding Rock. As shown in Figures 25 and 26, they represent the settlement of the surrounding rock and the horizontal convergence of the tunnel under the support of the prestressed anchor cable. This paper focuses on the deformation of the surrounding 


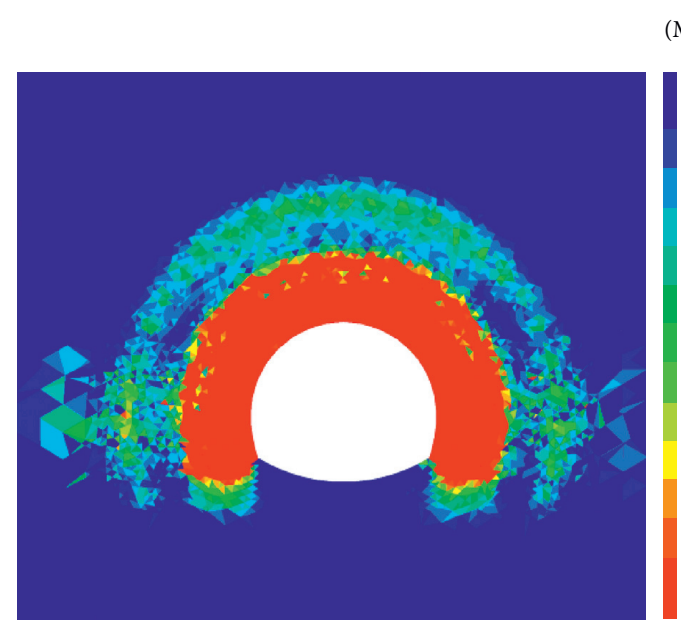

Section A
(Max. compression)

$$
\text { stress }
$$

$0.0000 E+00$

$-2.5000 E+05$

$-5.0000 E+05$

$-7.5000 E+05$

$-1.0000 E+06$

$-1.2500 E+06$

$-1.5000 E+06$

$-1.7500 E+06$

$-2.0000 E+06$

$-2.2500 E+06$

$-2.5000 E+06$

$-2.7500 E+06$

$-3.0000 E+06$

$-3.2500 E+06$

$-3.3000 E+06$

FIGURE 24: Stress of the surrounding rock under preloading $350 \mathrm{kN}$.

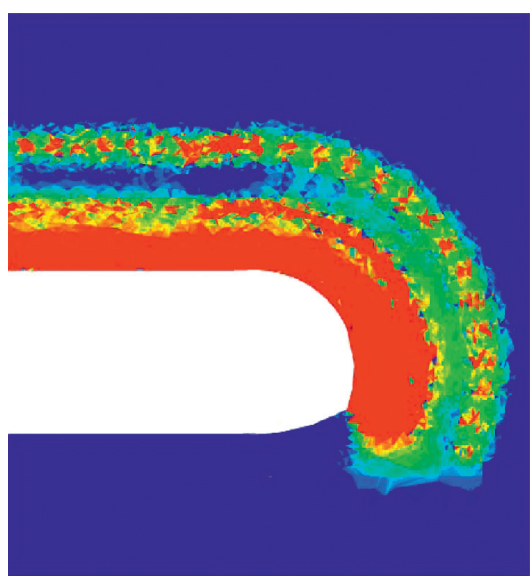

Section B
X-displacement

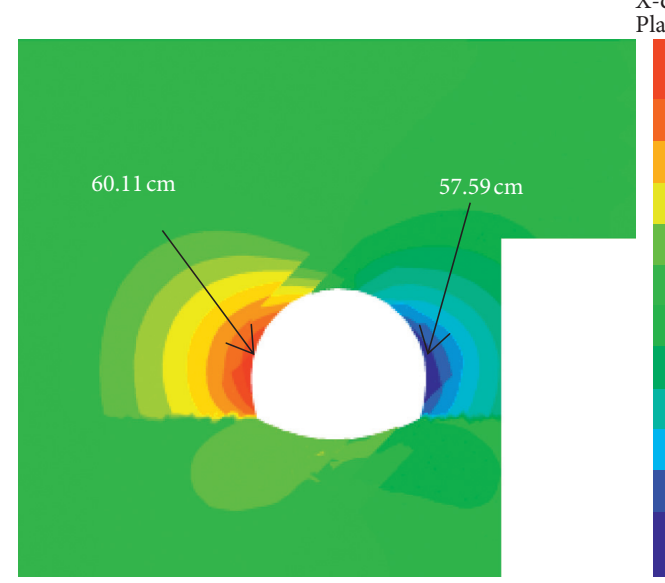

Prestressed $50 \mathrm{kN}$

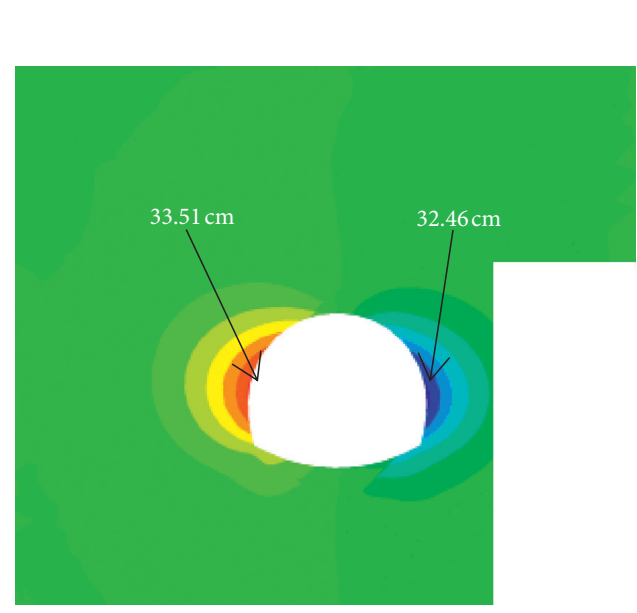

Prestressed $250 \mathrm{kN}$ Plane: active on

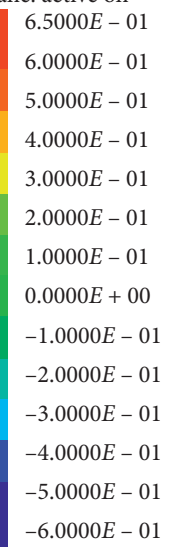

$-6.0000 E-01$

X-displacement
Plane: active on

$3.4000 E-01$
$3.0000 E-01$
$2.0000 E-01$
$1.0000 E-01$
$0.0000 E+00$
$-1.0000 E-01$
$-2.0000 E-01$
$-3.0000 E-01$
$-3.3000 E-01$

Figure 25: Horizontal displacement under different prestressing (Section A).

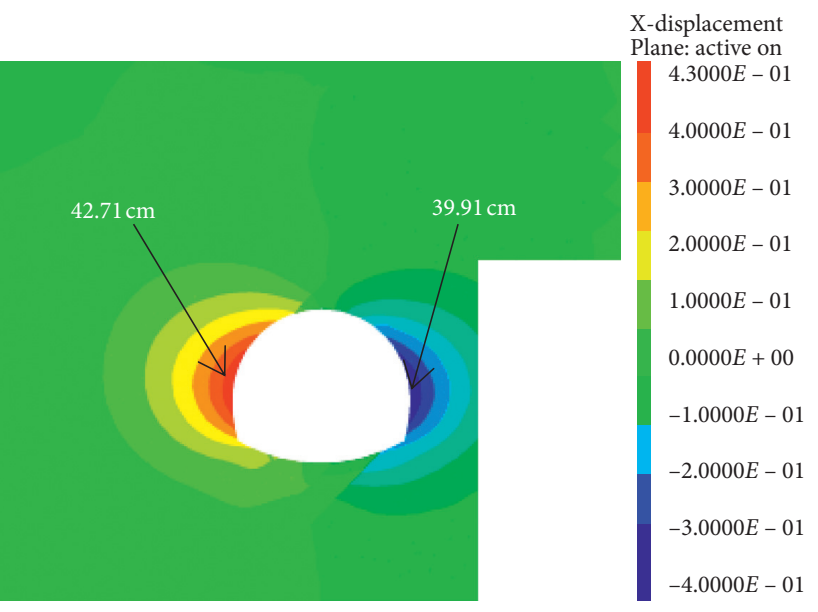

Prestressed $150 \mathrm{kN}$

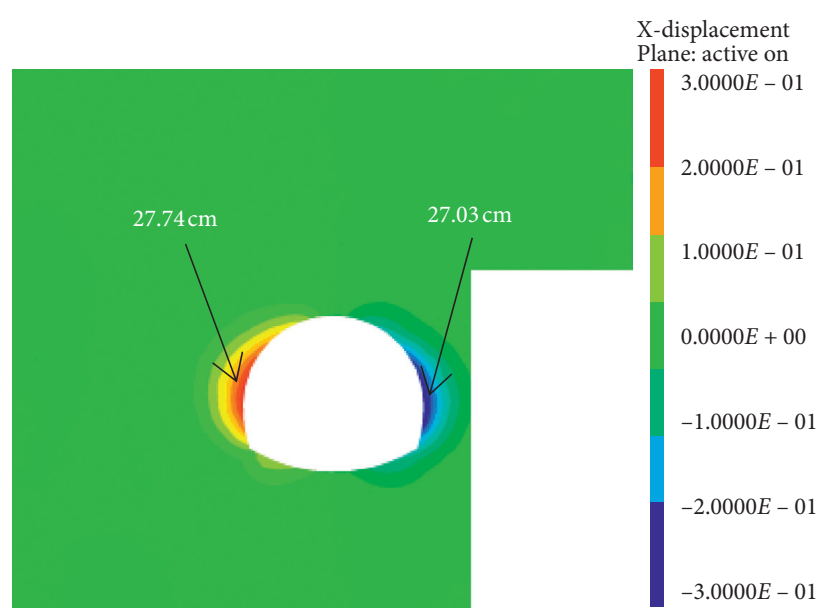

Prestressed $350 \mathrm{kN}$ rock under different prestress values. Compared with $50 \mathrm{kN}$ prestressing force, every $100 \mathrm{kN}$ of prestressing force increased, the tendency of vault subsidence decreased, with an average decrease of $10.9 \mathrm{~cm}$. However, this trend is not linear. With the continuous increase of prestress, dome subsidence reduction and prestressed increment ratio 


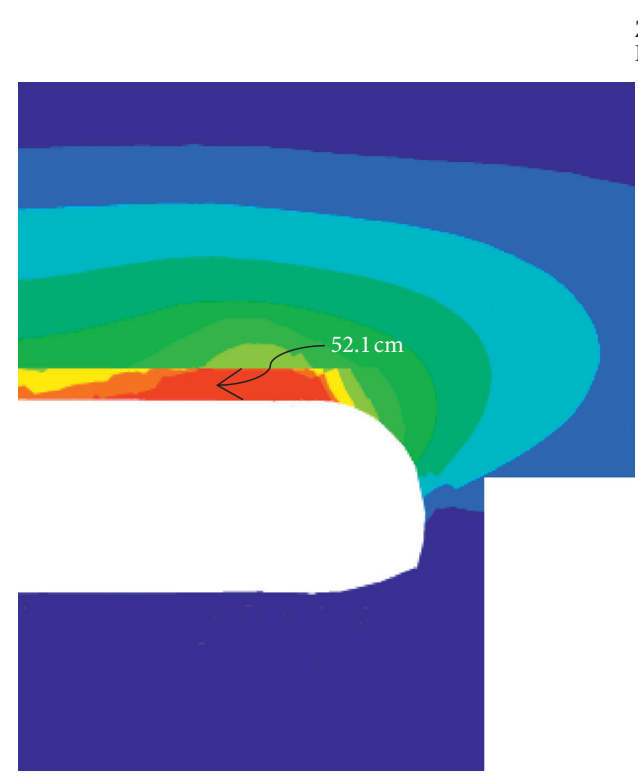

Prestressed $50 \mathrm{kN}$

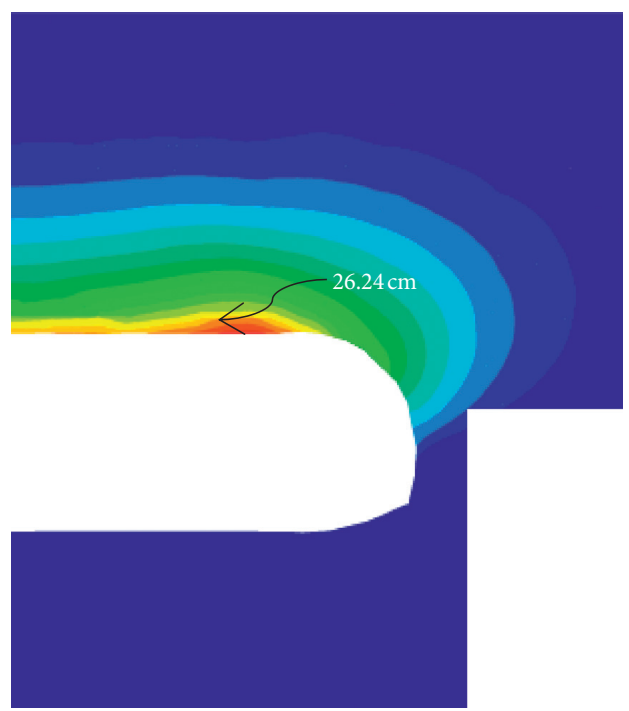

Prestressed $250 \mathrm{kN}$
Z-displacement Plane: active on

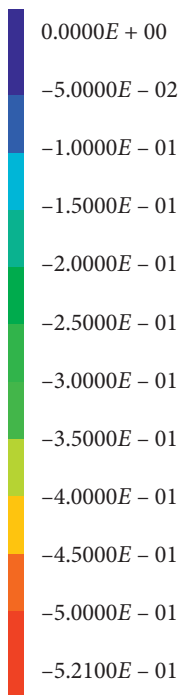

Z-displacement Plane: active on

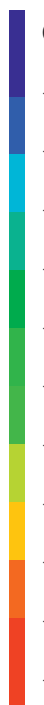

$0.0000 E+00$
$-2.5000 E-02$
$-5.0000 E-02$
$-7.5000 E-02$
$-1.0000 E-01$
$-1.2500 E-01$
$-1.5000 E-01$
$-1.7500 E-01$
$-2.0000 E-01$
$-2.2500 E-01$
$-2.5000 E-01$
$-2.7000 E-01$

FIGURE 26: Subsidence characteristics under different prestressing (Section B).
Z-displacement Plane: active on

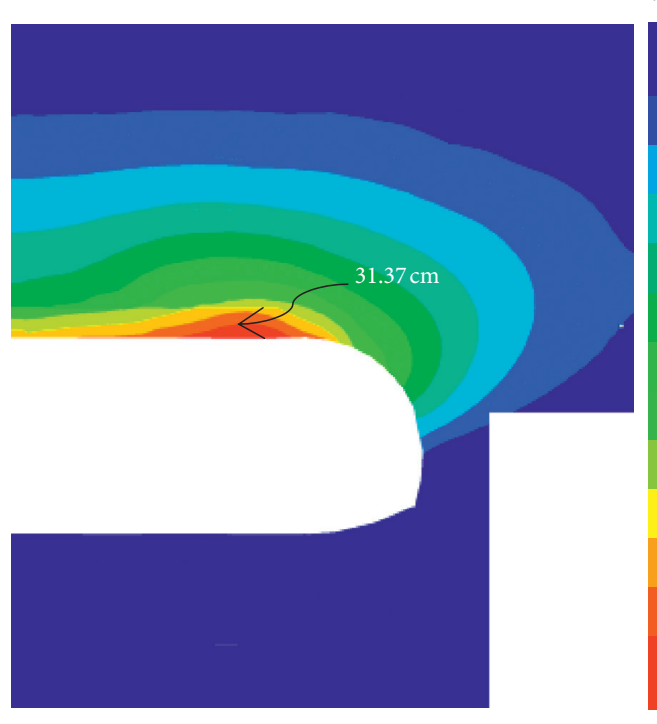

$0.0000 E+00$

$-2.5000 E-02$

$-5.0000 E-02$

$-7.5000 E-02$

$-1.0000 E-01$

$-1.2500 E-01$

$-1.5000 E-01$

$-1.7500 E-01$

$-2.0000 E-01$

$-2.2500 E-01$

$-2.5000 E-01$

$-2.7500 E-01$

$-3.0000 E-01$

$-3.2000 E-01$

Prestressed 150kN

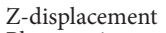
Plane: active on

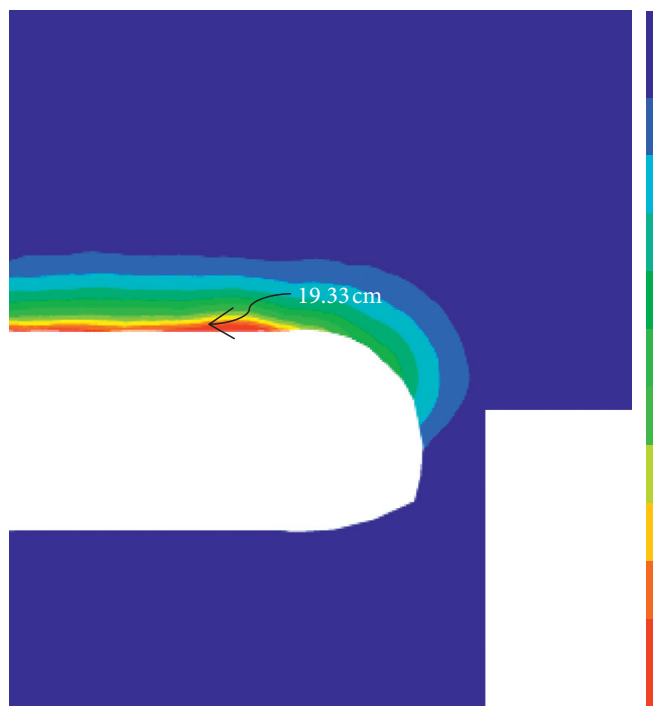

$0.0000 E+00$

$-2.0000 E-02$

$-4.0000 E-02$

$-6.0000 E-02$

$-8.0000 E-02$

$-1.0000 E-01$

$-1.2000 E-01$

$-1.4000 E-01$

$-1.6000 E-01$

$-1.8000 E-01$

$-2.0000 E-01$

$-2.1000 E-01$

Prestressed $350 \mathrm{kN}$ decreased significantly. When the prestress is increased from $50 \mathrm{kN}$ to $150 \mathrm{kN}$, the amount of vault sinking is reduced by $20.73 \mathrm{~cm}$. When the prestress is increased from $250 \mathrm{kN}$ to $350 \mathrm{kN}$, the amount of vault sinking is reduced by $6.91 \mathrm{~cm}$. The maximum amount of vault subsidence occurs at the position where the inclined shaft crosses the main hole so attention should be paid to this position during construction and monitoring. This paper also has analyzed Section A to obtain the horizontal deformation characteristics of the tunnel surrounding rock under different prestresses. According to the analysis, as the prestress value increases, the horizontal displacement of the tunnel slows down, but the trend is not linear. Under the prestressed anchor cable support, due to its unique joint structure, the deformation of the surrounding rock on the left is greater than that on the right, and the deformation is uneven. As the prestress gradually increases, the tendency of asymmetric deformation weakens. At the same time, the horizontal convergence deformation is also reduced, and its slowing trend is similar to that of vault sinking.

\section{Field Measurement and Analysis}

The complete field monitoring data can provide basic data for the implementation of tunnel support, which is an important guarantee for the consolidation and development of tunnel support engineering. Its main purpose is to analyze the monitoring data of the stability of the surrounding rock, master the dynamic and regularity of the surrounding rock of the tunnel, provide scientific basis for 


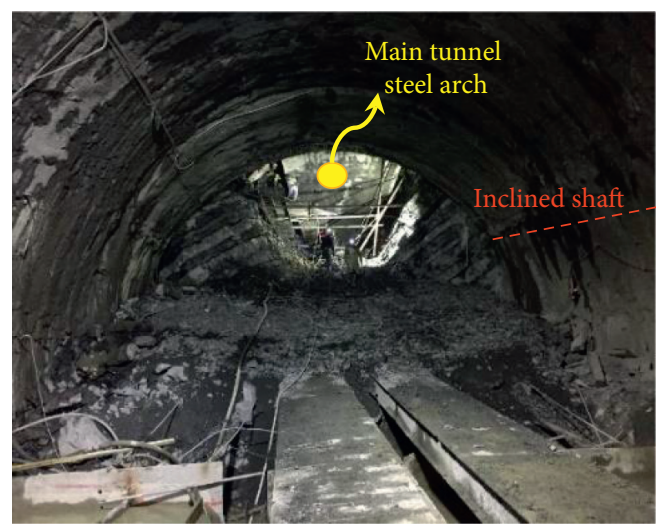

(a)

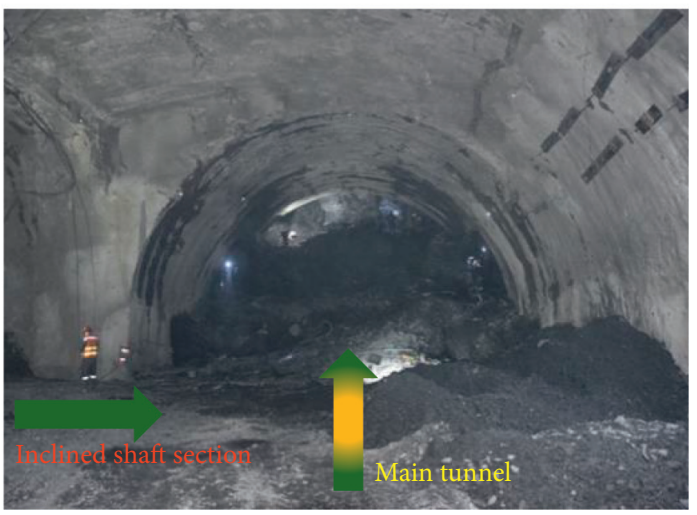

(b)

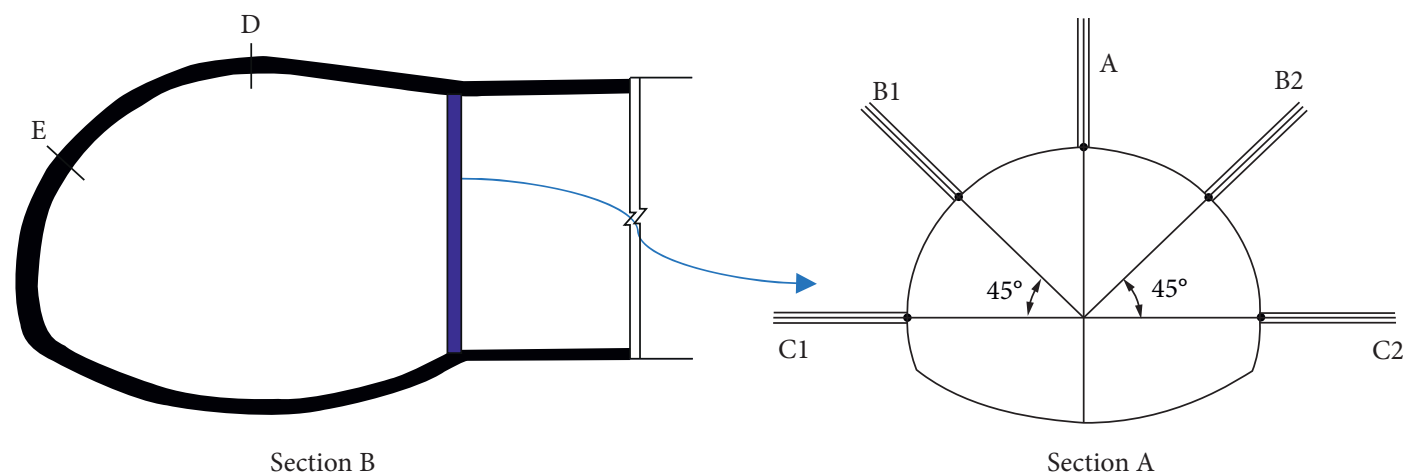

FIGURE 27: Construction of intersection and monitoring points: (a) the inclined shaft into the main tunnel and (b) the main tunnel driving.

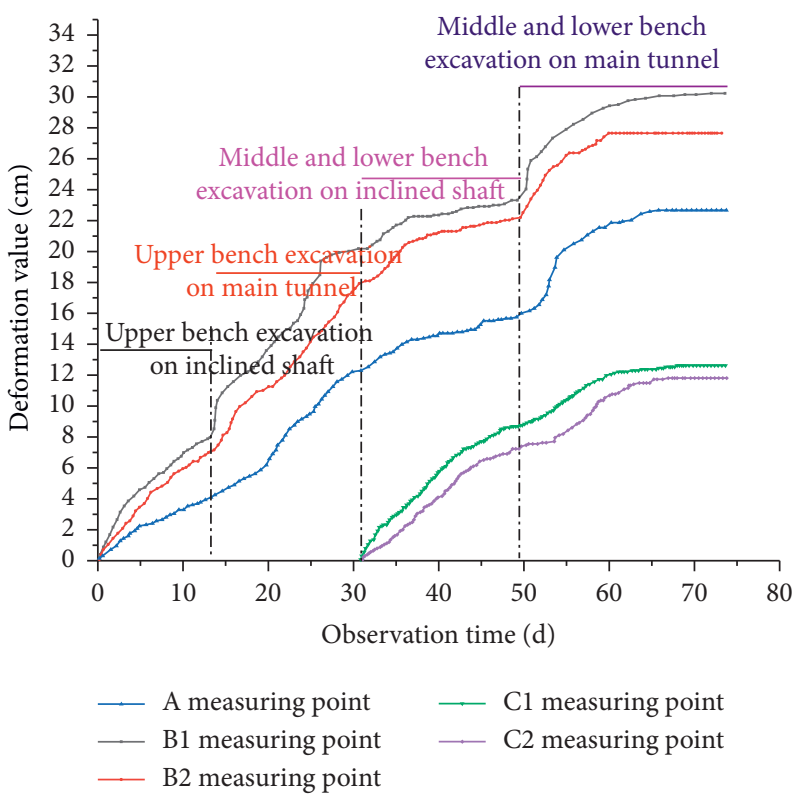

Figure 28: Deformation of Section A.

the daily dynamic management of the tunnel support, test the rationality of the support structure, design parameters and construction technology, modify and optimize the support parameters and reasonably determine the construction time of different support measures, and provide scientific basis through supervision. The survey data can be used as a standard to judge the quality inspection and acceptance of tunnel engineering. As shown in Figure 27, five displacement monitoring points are set near the last row of steel arch frame of the inclined shaft, i.e., Section A: 


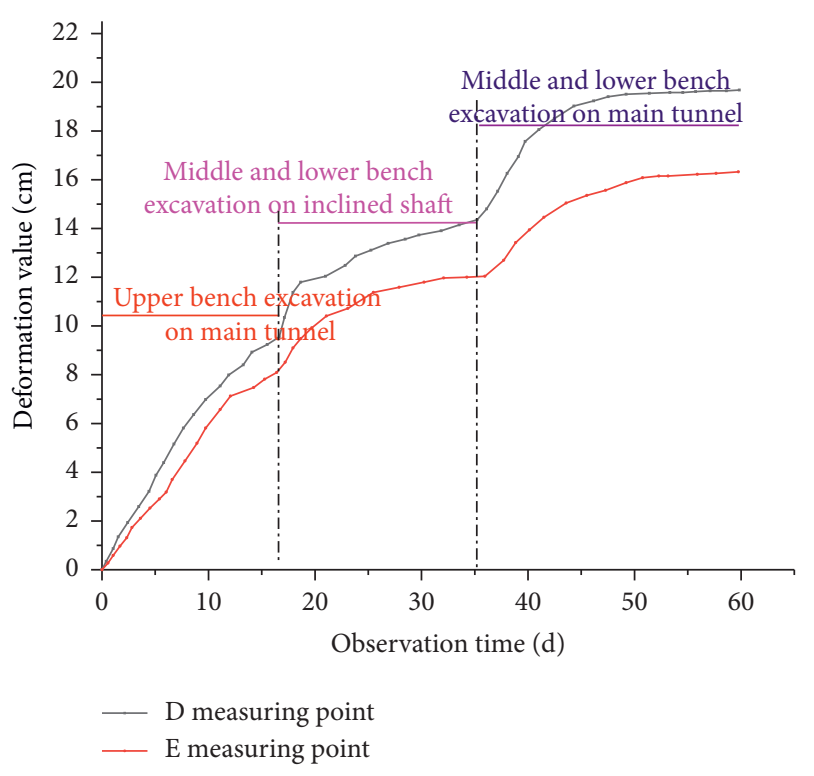

Figure 29: Deformation of Section B.

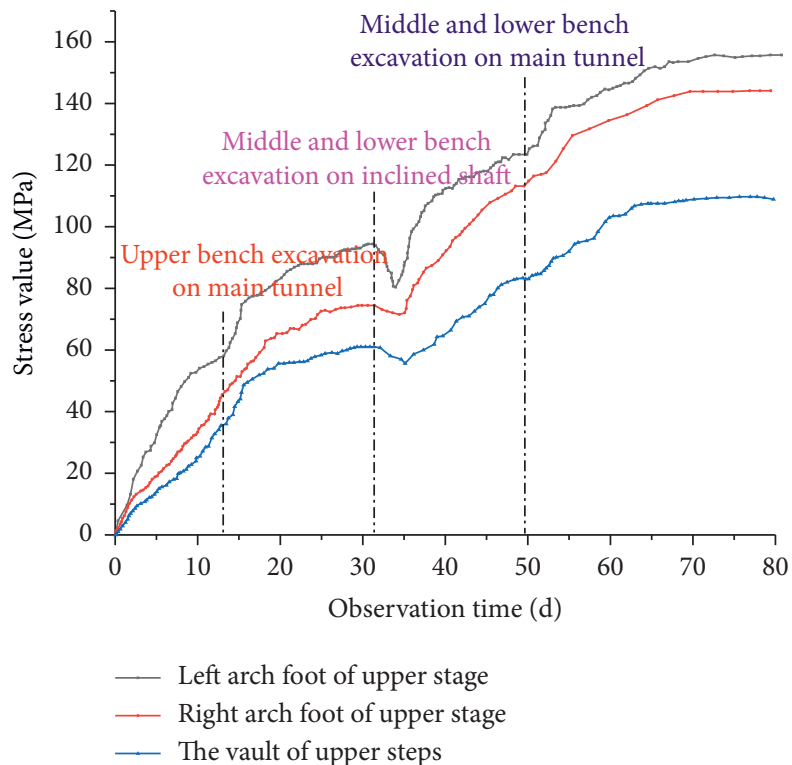

Figure 30: Stress of the steel arch.

arch crown, left-arch shoulder, right-arch shoulder, leftarch waist, and right-arch waist. The three stress monitoring points of steel arch are vault, left-arch shoulder, and right-arch shoulder. Two observation points of vault subsidence are arranged on Section B.

The deformation convergence of the surrounding rock in Section A is shown in Figure 28. The deformation of the surrounding rock tends to be stable at about 65 days, and the deformation of left-arch shoulder is the largest. After the upper bench excavation on Section A, the average deformation rate of the left spandrel is $0.61 \mathrm{~cm} / \mathrm{d}$. When the inclined shaft enters the main tunnel, the upper stage excavation stage of the main tunnel, the average deformation rate of point $\mathrm{B} 1$ of this section is $0.66 \mathrm{~cm} / \mathrm{d}$. In the third stage of the section, after the completion of the closed-loop, the deformation rate decreases obviously and tends to be stable. However, it has a disturbing effect on Section A, in the process of the lower part excavation of the main tunnel. As shown in Figure 29, the deformation of the surrounding rock in Section B tends to be stable after 45days. After the excavation of the upper bench, it increases rapidly in $0-10$ days, and in this process, the crown subsidence is $0.75 \mathrm{~cm}$ per day on average. During the excavation of the middle and lower steps in the inclined shaft and main tunnel, the deformation rate of the surrounding rock increases. After the inverted arch is closed, the deformation of the surrounding rock is gradually stable. 
The stress of steel arch in Section A is shown in Figure 30. The stress of the steel frame at the left-arch shoulder is the largest, but it does not exceed the yield strength. After the installation of the upper steel arch, the stress of the arch increases rapidly. After the excavation of the middle stage, because the steel arch of the upper stage is suspended, the stress of the arch decreases and then increases slowly with the deformation of the surrounding rock. The excavation of the main tunnel will increase the stress of the steel frame. When the inverted arch is excavated and closed completely, the stress of the steel arch is gradually stable.

\section{Conclusions}

Based on the mechanical model of the surrounding rock structure under the prestressed support, put forward the supporting design scheme of the $\mathrm{Mu}$ Zhai-ling tunnel intersection. Using numerical simulation and field measurement technology, the displacement and stress at the intersection were studied. The following conclusions are drawn:

(1) The increase of prestress can effectively increase the compressive capacity of the bearing arch. When the prestress increases from $0 \mathrm{MPa}$ to $1 \mathrm{MPa}$, the bearing capacity of the supporting structure increases from 2.8 $\mathrm{MPa}$ to $5.6 \mathrm{MPa}$. When the internal friction angle increases from 0.15 to 0.4 , the bearing capacity of the supporting structure increases from $3 \mathrm{MPa}$ to $6 \mathrm{MPa}$. When cohesion increases from $0 \mathrm{MPa}$ to $2 \mathrm{MPa}$, the bearing capacity of the support increases from $4 \mathrm{MPa}$ to $11 \mathrm{MPa}$.

(2) The numerical results show that, under the combined action of long and short anchor cables, the support resistance in the support area increases significantly. The effective prestressing force is effectively diffused in the support range, and the effective stress produced by the long and short anchor cables is superimposed on each other, finally forming the double-arch prestressing force expansion area.

(3) From the numerical simulation results, the deformation and vault settlement of the tunnel intersection decreases with the increase of prestress. When the prestressing force is $50 \mathrm{kN}$, the convergence deformation of the tunnel surrounding rock is $60.11 \mathrm{~cm}$. When the prestress is $350 \mathrm{kN}$, the deformation is only $27.74 \mathrm{~cm}$ and the vault settlement also decreased from $52.1 \mathrm{~cm}$ to $19.33 \mathrm{~cm}$. The increase of tunnel support resistance can reduce tunnel deformation.

(4) The measured data show that, under the control of high-prestressed support method, the maximum horizontal convergence of the tunnel is $32 \mathrm{~cm}$ and the maximum vault settlement is $23 \mathrm{~cm}$. The stress on the arch is also within the elastic range. The highprestressed support system can effectively control the deformation of large cross-section tunnel in soft rock and provide practical basis for the subsequent large deformation engineering of soft rock.

\section{Data Availability}

The data used to support the findings of this study are available from the corresponding author upon request.

\section{Conflicts of Interest}

The authors declare that they have no conflicts of interest.

\section{Acknowledgments}

This work was supported in part by the Research on Intelligent Construction Method and Technical System of Sichuan Tibet Railway Based on Active Control of Surrounding Rock Deformation (P2019G038).

\section{References}

[1] Z. Niedbalski, P. Małkowski, and T. Majcherczyk, "Application of the NATM method in the road tunneling works in difficult geological conditions-the Carpathian flysch," Tunnelling and Underground Space Technology, vol. 74, pp. 41-59, 2018.

[2] C. Zhang, C. Pu, R. Cao, T. Jiang, and G. Huang, "The stability and roof-support optimization of roadways passing through unfavorable geological bodies using advanced detection and monitoring methods, among others, in the Sanmenxia Bauxite Mine in China's Henan Province," Bulletin of Engineering Geology and the Environment, vol. 78, no. 7, pp. 5087-5099, 2019.

[3] G. B. Hemphill, Practical Tunnel Construction, Wiley, Hoboken, NJ, USA, 2013.

[4] X. Liu, Y. Zhu, X. Li et al., "Experimental research on singlelayer tunnel lining of steel fiber shotcrete," Rock and Soil Mechanics, vol. 30, no. 8, pp. 2320-2323, 2009.

[5] J. Z. Wen, Y.-X. Zhang, and C. Wang, "Back analysis of internal force of initial support in tunnel based on touch stress," Rock and Soil Mechanics, vol. 32, no. 8, pp. 2467-2472, 2011.

[6] H. Hongwei and X. Ling, "Study on deformation and internal force of surrounding rocks and initial support in Dafengyakou rock road tunnel," Chinese Journal of Rock Mechanics and Engineering, vol. 1, 2004.

[7] H. Wenzheng, X. Linsheng, and W. Lili, "Theoretical back analysis of internal forces of primary support in deep tunnels," Journal of Engineering Science \& Technology Review, vol. 12, no. 1, pp. 18-26, 2019.

[8] S. S. Vardakos, M. S. Gutierrez, and N. R. Barton, "Backanalysis of Shimizu Tunnel no. 3 by distinct element modeling," Tunnelling and Underground Space Technology, vol. 22, no. 4, pp. 401-413, 2007.

[9] Q. Wang, B. Jiang, S. C. Li et al., "Experimental studies on the mechanical properties and deformation \& failure mechanism of U-type confined concrete arch centering," Tunnelling and Underground Space Technology, vol. 51, pp. 20-29, 2016.

[10] X. Chang, X. Luo, C. Zhu, and C. Tang, "Analysis of circular concrete-filled steel tube (CFT) support in high ground stress conditions," Tunnelling and Underground Space Technology, vol. 43, pp. 41-48, 2014.

[11] M. Hisatake and S. Ohno, "Effects of pipe roof supports and the excavation method on the displacements above a tunnel face," Tunnelling and Underground Space Technology, vol. 23, no. 2, pp. 120-127, 2008. 
[12] Z. Zhang, H. Li, H. Liu, G. Li, and X. Shi, "Load transferring mechanism of pipe umbrella support in shallow-buried tunnels," Tunnelling and Underground Space Technology, vol. 43, pp. 213-221, 2014.

[13] G. Li, F. Ma, J. Guo, H. Zhao, and G. Liu, "Study on deformation failure mechanism and support technology of deep soft rock roadway," Engineering Geology, vol. 264, Article ID 105262, 2020.

[14] Q. Chang, H. Zhou, D. Li et al., "Stability principle of extremely rigid secondary support for soft and broken rock roadway," Journal of Mining \& Safety Engineering, vol. 24, no. 2, pp. 169-177, 2007.

[15] D. Zhang, S. Liu, and S. Ren, "Research on selection of steel and steel grid for tunnel support in softrock with high geostress," Chinese Journal of Rock Mechanics and Enggineering, vol. 33, no. 11, pp. 2258-2266, 2014.

[16] G. Wu, W. Chen, X. Tan et al., "Performance of new type of foamed concrete in supporting tunnel in squeezing rock," International Journal of Geomechanics, vol. 20, no. 2, Article ID 4019173, 2020.

[17] H. Wang, W.-Z. Chen, X.-J. Tan, H.-M. Tian, and J.-J. Cao, "Development of a new type of foam concrete and its application on stability analysis of large-span soft rock tunnel," Journal of Central South University, vol. 19, no. 11, pp. 3305-3310, 2012.

[18] K. Wu and Z. Shao, "Study on the effect of flexible layer on support structures of tunnel excavated in viscoelastic rocks," Journal of Engineering Mechanics, vol. 145, no. 10, Article ID 4019077, 2019.

[19] J. Sun and S. Wang, "Rock mechanics and rock engineering in China: developments and current state-of-the-art," International Journal of Rock Mechanics and Mining Sciences, vol. 37, no. 3, pp. 447-465, 2000.

[20] H. Manchao, G. Yubing, and G. Weili, "Large deformation support for engineering soft rocks," Soft Rock Mechanics and Engineering, pp. 455-476, 2020.

[21] H. Kang, "Support technologies for deep and complex roadways in underground coal mines: a review," International Journal of Coal Science \& Technology, vol. 1, no. 3, pp. 261-277, 2014.

[22] Y. Chunan, "Stability analysis of U-steel yieldable support," Chinese Journal of Rock Mechanics and Engineering, vol. 21, no. 11, pp. 1672-1675, 2002.

[23] Q. Liu, J. Chai, S. Chen et al., "Monitoring and correction of the stress in an anchor bolt based on pulse pre-pumped brillouin optical time domain analysis," Energy Science \& Engineering, vol. 8, 2020.

[24] H.-P. Kang, J.-H. Wang, and J. Lin, "High pretensioned stress and intensive bolting system and its application in deep roadways," Journal of China Coal Society, vol. 32, pp. 12331238, 2007.

[25] K. Hong-Pu, L. Jian, and W. Yong-Zheng, "Development of high pretensioned and intensive supporting system and its application in coal mine roadways," Procedia Earth and Planetary Science, vol. 1, no. 1, pp. 479-485, 2009.

[26] K. Hongpu, L. Jian, and Z. Bingchuan, "Study on small borehole pretensioned cable reinforcing complicated roadway," Chinese Journal of Rock Mechanics and Engineering, vol. 22, no. 3, pp. 387-390, 2003.

[27] N. Zhang, C. Wang, M. Gao et al., "Roadway support difficulty classification and controlling techniques for Huainan deep coal mining," Chinese Journal of Rock Mechanics and Engineering, vol. 12, no. 10, 2009.
[28] J. Lin, Y. Shi, Z. Y. Sun et al., "Large scale model test on the distribution characteristics of the prestressed field of endanchored bolts," Chinese Journal of Rock Mechanics and Engineering, vol. 35, no. 11, pp. 2237-2247, 2016.

[29] L. R. Alejano and A. Bobet, "Drucker-prager criterion," The ISRM Suggested Methods for Rock Characterization, Testing and Monitoring: 2007-2014, Springer, Berlin, Germany, 2012.

[30] L. B. Colmenares and M. D. Zoback, "A statistical evaluation of intact rock failure criteria constrained by polyaxial test data for five different rocks," International Journal of Rock Mechanics and Mining Sciences, vol. 39, no. 6, pp. 695-729, 2002.

[31] W. Liu, X. Qian, T. Li, Y. Zhou, and X. Zhu, "Investigation of the tool-rock interaction using Drucker-Prager failure criterion," Journal of Petroleum Science and Engineering, vol. 173, pp. 269-278, 2019.

[32] U. Sellgren and U. Olofsson, "Application of a constitutive model for micro-slip in finite element analysis," Computer Methods in Applied Mechanics and Engineering, vol. 170, no. 1-2, pp. 65-77, 1999.

[33] Z. Yin, H. Huang, F. Zhang et al., "Three-dimensional distinct element modeling of fault reactivation and induced seismicity due to hydraulic fracturing injection and backflow," Journal of Rock Mechanics and Geotechnical Engineering, vol. 12, 2020.

[34] G. Li, Y. Hu, Q.-B. Li, T. Yin, J.-X. Miao, and M. Yao, "Inversion method of in-situ stress and rock damage characteristics in dam site using neural network and numerical simulation-a case study," IEEE Access, vol. 8, pp. 46701-46712, 2020. 